\title{
LUT
}

University

\section{Trends in the global cement industry and opportunities for long-term} sustainable CCU potential for Power-to-X

Farfan Javier, Fasihi Mahdi, Breyer Christian

This is a Author's accepted manuscript (AAM) version of a publication

published by Elsevier

in Journal of Cleaner Production

DOI: $10.1016 /$ j.jclepro.2019.01.226

Copyright of the original publication: (c) 2019 Elsevier Ltd.

Please cite the publication as follows:

Farfan, J., Fasihi, M., Breyer, C. (2019). Trends in the global cement industry and opportunities for long-term sustainable CCU potential for Power-to-X. Journal of Cleaner Production, vol. 217, pp. 821-835. DOI: 10.1016/j.jclepro.2019.01.226

This is a parallel published version of an original publication.

This version can differ from the original published article. 


\title{
Trends in the global cement industry and opportunities for long-term sustainable CCU potential for Power-to-X
}

\author{
Javier Farfan", Mahdi Fasihi, Christian Breyer \\ Lappeenranta University of Technology, School of Energy Systems
}

\begin{abstract}
:
In order to achieve targets set by the Paris Agreement and limit global average temperature increase to well below $2{ }^{\circ} \mathrm{C}$ above pre-industrial levels, an assessment and a low carbon transformation is needed for all types of human activities. Cement production is associated with high levels of $\mathrm{CO}_{2}$ emissions, with an average of $866 \mathrm{~kg}_{\text {of }} \mathrm{CO}_{2}$ emitted per ton of cement produced. This positions the cement industry as one of the main sources of anthropogenic greenhouse gas emissions accounting for about $5 \%$ of the total, right after the chemical industry and more relevant than the iron and steel industry. About $50 \%$ of the emissions are caused by burnt fuel, related transport and other inputs, which can be currently substituted by other measures. However, the $\mathrm{CO}_{2}$ emissions which originate from input limestone cannot be avoided. These process $\mathrm{CO}_{2}$ emissions present a potential for carbon capture and utilisation. This research proposes a global potential analysis of CCU as a possible solution for the $\mathrm{CO}_{2}$ emissions of cement production. Cement $\mathrm{CCU}$ may establish a substantial route to use $\mathrm{CO}_{2}$ for synthetic hydrocarbons production and thus contribute towards mitigating the nonsubstitutable $\mathrm{CO}_{2}$ content of the limestone-based raw material. The production of renewable electricity based synthetic hydrocarbon fuels by $\mathrm{CO}_{2}$ captured from cement plants, counts for a potential to produce between $3639 \mathrm{TWh}_{\text {th }}$ and $7355 \mathrm{TWh}_{\text {th }}$ of liquid hydrocarbons, or 6298 $\mathrm{TWh}_{\text {th }}$ and $12723 \mathrm{TWh}_{\text {th }}$ of synthetic natural gas, or a mix of both at the expected global cement peak production in 2040 .
\end{abstract}

Keywords: Cement, GHG emissions, power-to-fuels, carbon capture, carbon utilisation

\section{Nomenclature}

$\begin{array}{ll}\mathrm{BAU} & \text { Business as usual } \\ \mathrm{BCSa} & \text { Best case scenario - alternative fuels } \\ \mathrm{BCSe} & \text { Best case scenario - electric } \\ \mathrm{CaCO}_{3} & \text { Limestone } \\ \mathrm{CaL} & \text { Calcium looping } \\ \mathrm{CaO} & \text { Lime } \\ \mathrm{CC} & \text { Carbon capture } \\ \mathrm{CCS} & \text { Carbon capture and storage } \\ \mathrm{CCU} & \text { Carbon capture and utilisation } \\ \mathrm{CO}_{2} & \text { Carbon dioxide } \\ \mathrm{CO}_{2 \mathrm{eq}} & \text { Carbon dioxide equivalent } \\ \mathrm{CSII}^{\mathrm{N}} & \text { Cement sustainability initiative target } \\ \text { DAC } & \text { Direct air capture } \\ \text { FLh } & \text { Full load hours } \\ \mathrm{GDP} & \text { Gross domestic product } \\ \mathrm{GHG} & \text { Greenhouse gases } \\ \mathrm{HHV} & \text { High heating value } \\ \text { LCOE } & \text { Levelised cost of electricity }\end{array}$




$\begin{array}{ll}\text { MENA } & \text { Middle East and North Africa } \\ \text { Mt } & \text { Megaton } \\ \text { MWh } & \text { Megawatt hour, thermal } \\ \text { PtG } & \text { Power-to-gas } \\ \text { PtL } & \text { Power-to-liquids } \\ \text { PtX } & \text { Power-to-X } \\ \text { RE } & \text { Renewable Energy } \\ \mathrm{R}^{2} & \text { Coefficient of determination } \\ \text { SAARC } & \text { South Asian Association for Regional Cooperation } \\ \text { SNG } & \text { Synthetic natural gas } \\ \text { TWh } & \\ \text { TWh }_{\text {l }} & \text { Terawatt hour, thermal } \\ \text { WBCSD } & \text { Terawatt hour, electric } \\ \end{array}$

\section{Highlights}

- The cement industry is responsible for up to $8 \%$ of anthropogenic $\mathrm{CO}_{2}$ emissions.

- $50 \%$ of the $\mathrm{CO}_{2}$ currently emitted during cement production comes from raw materials.

- The only option for partly decarbonising cement production is carbon capture.

- The captured carbon from cement processing can be used to produce synthetic fuels.

- Up to $5389 \mathrm{TWh}_{\text {th }}$ of synthetic gas can be produced from non-avoidable cement-based emissions in 2050.

\section{Introduction}

The cement industry produces the second most consumed product by weight in the world after steel, utilising roughly $1.9 \%$ of the global electricity generation [1, 2]. Thereby releasing globally from $5 \%$ to $8 \%$ of anthropogenic $\mathrm{CO}_{2}$ emissions $[3,4,5,6]$. The industry uses an average global energy demand of $1.025 \mathrm{MWh}_{\text {th }}$ and releases greenhouse gas (GHG) emissions of $866 \mathrm{~kg}$ of $\mathrm{CO}_{2 \mathrm{eq}}$ per metric ton (referred just as ton in the rest of the paper) of clinker, respectively [4]. Furthermore, the global cement industry has grown by a factor of 25 compared to 1950 's level, increasing capacity by $73 \%$ from just 2005 to 2013 [5]. Moreover, China produced and consumed more cement between 2011 and 2013 than the United States of America in the previous 100 years [5], adding up to around $3.8 \mathrm{Gt}$ of cement production and $3.2 \mathrm{Gt}$ of $\mathrm{CO}_{2 \mathrm{eq}}$ emissions and $3.895 \mathrm{TWh}_{\mathrm{th}}$ of energy consumed in 2012 [6].

However, reducing emissions from the process of cement making is not so straight forward, since it depends on different factors. According to [4] and [7], roughly 50\% of the GHG emissions from the cement manufacturing process are material-derived, $40 \%$ are fuel-derived, electricity accounts for $5 \%$ of the emissions and transport generates the residual $5 \%$. The GHG emissions can depend on factors such as technology used, fuel type, emission control system, geographic location, and the source of electrical power [4]. Emissions from the raw material are due to the chemical composition of limestone $\left(\mathrm{CaCO}_{3}\right)$, which through thermal processing releases $\mathrm{CO}_{2}$ to reduce the compound to lime $(\mathrm{CaO})$, the core component of cement.

Figure 1 shows a simplified flow diagram of the cement manufacturing process from mining to final product. Details of the manufacturing process are provided by $[8,9]$. Several stages of the cement production process can be fully decarbonised. Electricity can be produced from renewable sources [10] and carbon-neutral fuels can be generated [11] to use for the 
transportation of cement and provide the required heating for thermal processing. The thermal processing can also be done by electricity [12] or direct solar energy [13] instead of fuels, but the material-derived emissions cannot be easily avoided.

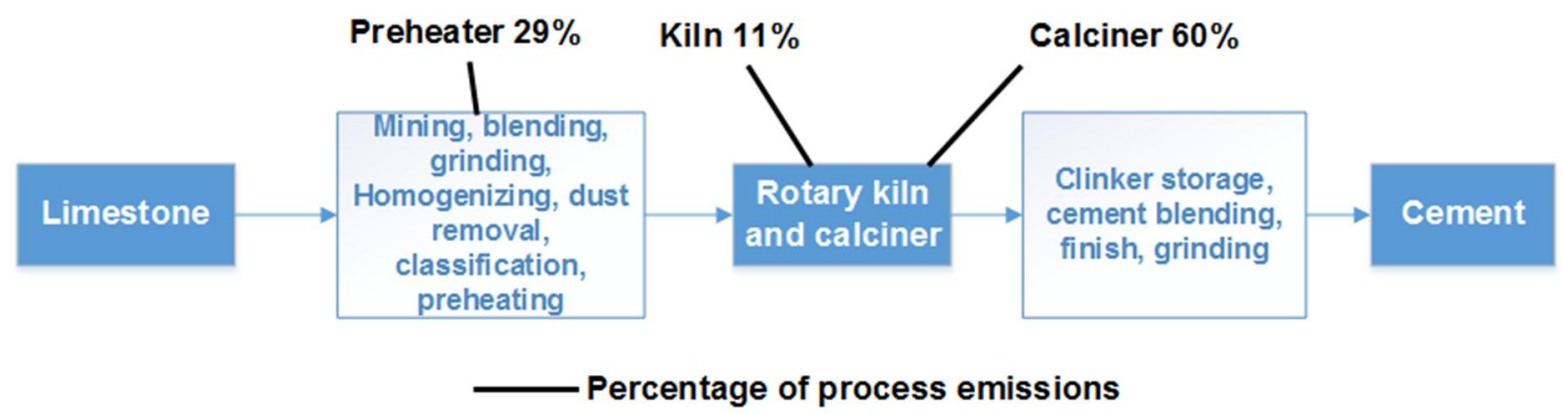

Figure 1: Simplified flow diagram of the cement manufacturing process. The percentages of process emissions are estimated and exclude the steps before preheating (mining, grinding, preheating, etc.), and after the cement production (packaging, transportation).

Nevertheless, in order to achieve the targets of the Paris Agreement [14] and prevent global average temperature to raise above $1.5^{\circ} \mathrm{C}$ pre-industrial levels, it is necessary to get as close to zero GHG emissions by 2050 as possible. The power sector can be transformed to zero GHG emissions in a relatively easier manner, if strong commitments are made, as the resources and conditions are proven to exist already, and expected to further develop in the next few years $[10,15]$. Whereas, cement manufacturing as it is, is incompatible with the zero emissions requirement of the near future. Limestone is considered equivalent to coal by [16], as the thermal processing of limestone releases a similar amount of $\mathrm{CO}_{2}$ as the combustion of coal for its thermal energy. Also, both limestone and coal are carbon sources of fossil origin. Also in [16] cement is proposed, just as coal, an important candidate for carbon capture, though it is pointed out in the same study that carbon capture and storage (CCS) is not a viable strategy for cement emissions, just as it has proven to be in the case of coal-fired power plants. CCS is highly dependent of geographical and geological conditions and it would double the capital and operational costs of a cement plant [16].

Alternatives to limestone for cement production are also proposed in [16], some even with potential of negative carbon emissions. However, switching to such alternatives are still farfetched, as the properties and durability of alternative compounds are still to be tested, both in laboratories and in real life applications. Therefore, in this research yet another alternative is proposed, carbon capture and utilisation (CCU). CCU has the potential of compensating for the offset in capital and operational expenditures added by adapting carbon capture to the cement process. By utilising the captured carbon to produce synthetic (and valuable) hydrocarbon fuels or chemicals [11, 17], it is possible to compensate to some extent, both the cost of carbon capture, and also carbon emissions of the otherwise utilised fossil derived hydrocarbon fuels, at least during the transition period. One type of CCU in the case of cement and concrete that has considerable research behind is the carbonation curing of concrete masonry blocks [18-21]. These precast blocks can absorb between 17\% [19] and 25\% [20] of their mass in $\mathrm{CO}_{2}$ while perceiving an increase in their compressive strength. However, precast concrete represents only $20 \%$ to $30 \%$ of the global market of concrete [20].

After the phase out of fossil fuels in the cement production process, the net GHG emissions of the cement process cannot be avoided anymore. However, it may still lower the costs of synthetic hydrocarbon production for a lower $\mathrm{CCU}$ cost compared to the $\mathrm{CO}_{2}$ direct air capture 
alternative. Multiple technologies have been proposed for carbon capture from the cement process. Amine scrubbing, already available for other processes shows high potential, but also new concepts such as calcium looping $(\mathrm{CaL})$ could eventually prove to be advantageous alternatives. Carbon capture techniques can be further improved by oxy-combustion. A technoeconomic analysis of the different technologies and their forecasted efficiencies are presented by Leeson et al. [22]. Reported efficiencies vary widely in forecasts (from 52\% to 94\%) even for the same analysed process $(\mathrm{CaL})$, and further scepticism should be given to overly high efficiencies, taking into account that none of these technologies are yet commercially available for the cement industry. The assumed incremental efficiencies for carbon capture (expecting the process to improve over time) are 60\%,70\% and 80\% for 2030, 2040 and 2050 respectively, as the technology evolves [23].

\section{Methodology and Data}

A comprehensive list of all cement production sites, as well as their operators, capacities, and host countries were obtained from the Global Cement Directory [24], which were compared and complemented with [25], and further compiled into a database. The database on a country basis is provided in the supplementary material to this research. Furthermore, each cement manufacturing location obtained from the aforementioned sources was then localised through satellite aerial view. All of the active and registered cement factories across the world are plotted and shown in Figure 2.

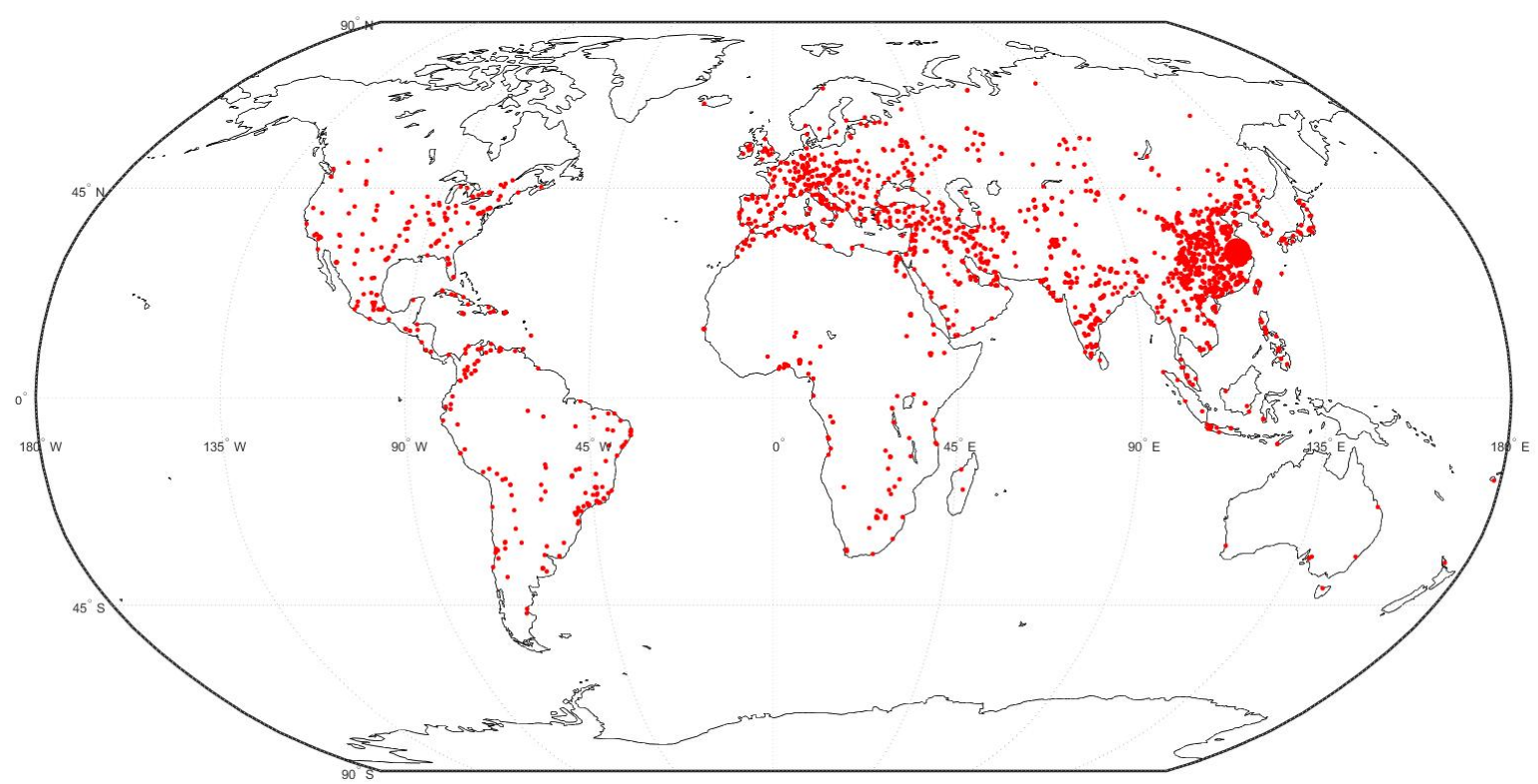

Figure 2: Global cement production sites. Larger circles represent production sites of significantly higher capacity than the others. Data are obtained from [24, 25].

In Figure 2 are plotted the over 2300 operating cement production sites from a total of over 2500 currently registered (the difference being deactivated, under construction or in planning plants). A few of them (1.3\%) are capable of producing several tens of megatons (Mt) per year, some others producing just kilotons of special concretes per year, but the majority of the production sites (63\% of the active cement plants) produce between $0.4 \mathrm{Mt}$ to $2 \mathrm{Mt}$ per year. Active cement plants by the end of 2016 registered in the database sum up to a production capacity of $3746 \mathrm{Mt}$ of cement per year. It is clear from Figure 2 that the cement is produced globally, but mostly consumed locally, as limestone is a rather commonly available raw 
material and the production process and machinery are simple enough to be deployed close to demand sites. Figure 3 shows how the cement plants are distributed by capacity. As it can be seen, globally $83 \%$ of the cement is produced in plants with capacities of over 1 Mt per year, and $28 \%$ is produced in plants with capacities of over 4 Mt per year.
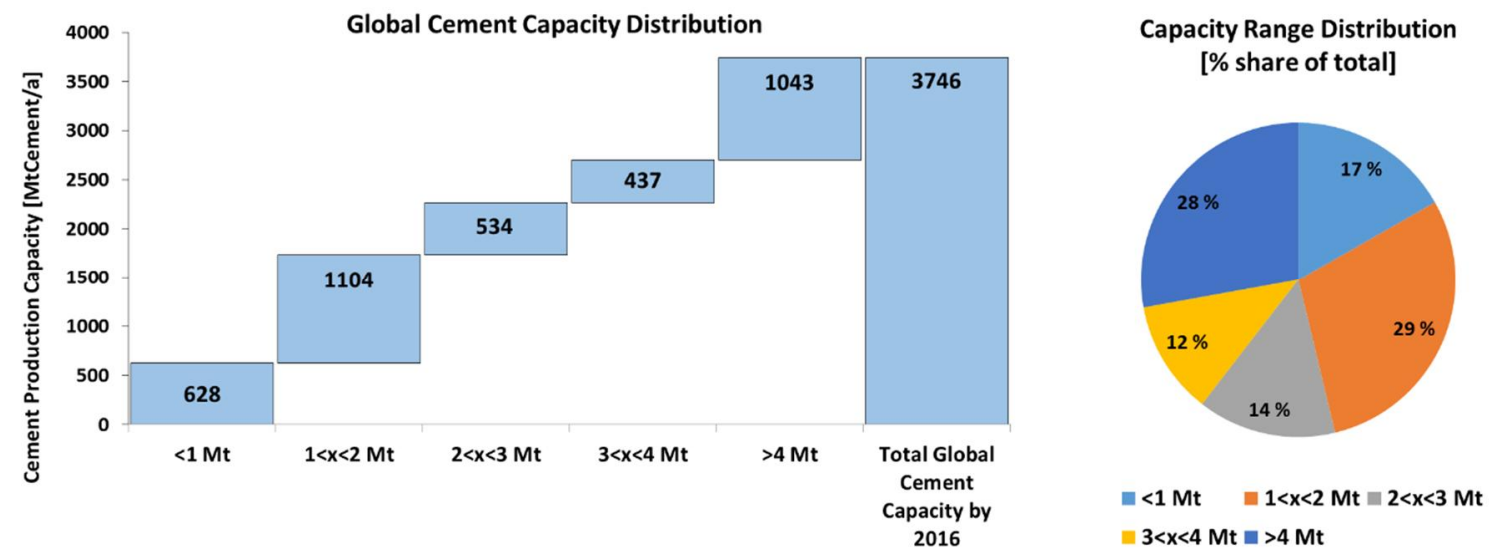

Figure 3: Distribution of installed capacities by capacity range.

Cement production, as shown in Figure 2, tends to be close to population centres, as those places represent the target consumers of the product. As it is used for housing and infrastructure such as roads, hospitals, schools, sewage, etc., which is further driven by the cost structure and the high density of cement leading to fast rising cost fractions of transportation as a function of distance. Much like population, China holds the highest capacity in a single country with $36.8 \%$ of the global cement production. Other countries with high production capacity shares of cement are India (8.7\%), United States of America (3.3\%), Russia (3.0\%), Vietnam (2.8\%), Turkey (2.6\%), Brazil (2.3\%) and Iran (2.3\%). Together the top 10 cement producing countries hold $65.7 \%$ of the total global production.

An extract of the database and the main countries across the world in cement production capacity are presented in Table 1 . The $\mathrm{CO}_{2 \text { eq }}$ emissions are estimated based on [25] records by taking an average of the emissions per ton of cement in the past 10 years in each region, as the emissions depend to some degree on the location and quality of the raw material.

Table 1: Main countries in the cement industry globally, region distributions, and their respective estimated emissions. The capacity numbers are for end of 2016 and equivalent to a full year of production. Data are taken from Global Cement Directory [24]. The $\mathrm{CO}_{2 \text { eq }}$ emissions estimate is based on [25].

\begin{tabular}{lll}
\hline Country & Cement Capacity $[\mathrm{Mt} / \mathrm{a}]$ & $\mathrm{CO}_{2 \mathrm{eq}}$ emissions estimated [Mtco2eq $\left./ \mathrm{a}\right]$ \\
China & 1367.0 & 1170.1 \\
India & 324.6 & 276.3 \\
United States & 120.8 & 112.4 \\
Russia & 110.8 & 95.2 \\
Vietnam & 105.6 & 89.8 \\
Turkey & 96.4 & 82.1 \\
Brazil & 85.5 & 73.4 \\
Iran & 84.7 & 72.1 \\
Saudi Arabia & 73.5 & 62.5 \\
Indonesia & 71.7 & 61.0 \\
\hline
\end{tabular}


Region

Global

Top10

EU-28

Share Top 10

Share EU-28

China only
Cement Capacity [Mt/a]

3713.4

2440.6

275.4

$65.1 \%$

$7.3 \%$

$36.5 \%$
$\mathrm{CO}_{2 \text { eq }}$ emissions estimated [MtcO2eq/a]

3206.9

2094.9

236.6

$65.3 \%$

$7.4 \%$

$36.5 \%$

Figure 4 shows the total active production capacity installed in regions. The scale was set as logarithmic since the difference in active installed capacities has large variations from region to region, especially when compared with China.

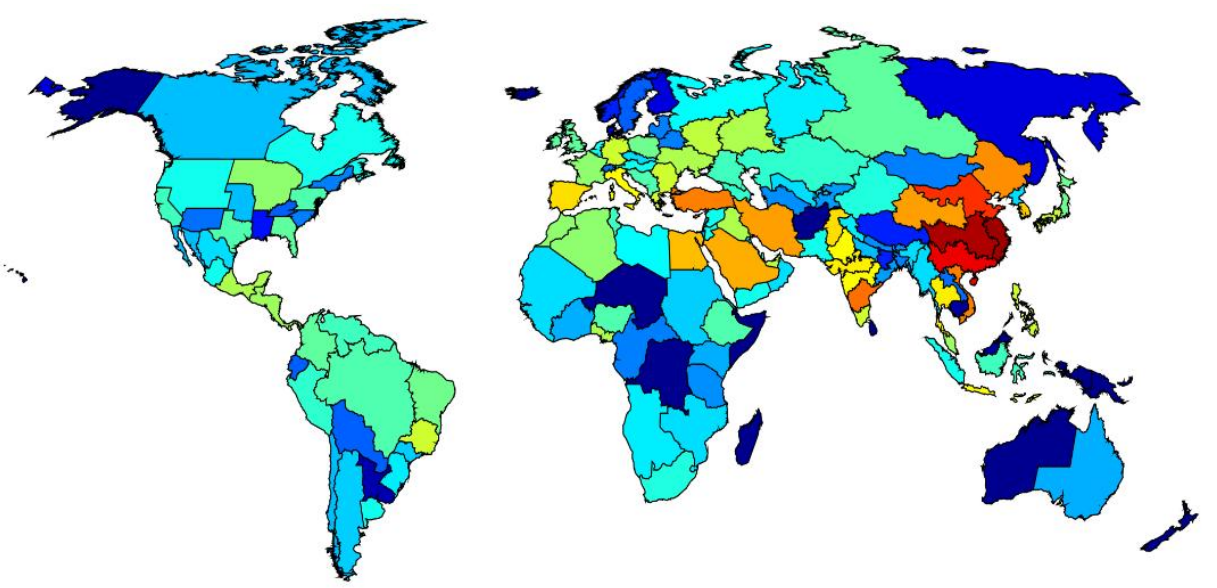

Total global capacity $3713.4 \mathrm{MtCement/a}$

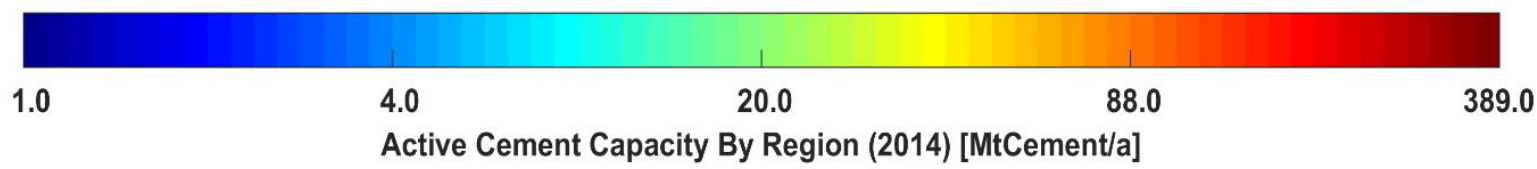

Figure 4: Global cement production capacity installations structured in regions shown in logarithmic scale.

So far, proposed roadmaps for carbon reduction as mentioned in $[4,5,6,17,26,27,28]$ present de-carbonisation strategies for replacing fossil fuels with synthetic or carbon neutral ones and using RE sources, which still leaves a potential of around $1.56 \mathrm{Gt}$ of GHG emissions to be tackled by 2050 , while double of that is already being emitted today. Some of these strategies can (and are expected to) be implemented to reduce GHG emissions immediately, but the insufficiency of the approach to fully eliminate $\mathrm{CO}_{2 \text { eq }}$ emissions is what sets the stage for carbon capture strategies.

Currently, the situation is as plotted in Figure 5, showing the consumption of cement per capita compared to the gross domestic product (GDP) per capita globally. The red line (generated by the function of Equation 1) represents the projected demand of cement per capita as a function of development of GDP per capita, as van Ruijven et al. [29] found a strong correlation between GDP and cement and steel usage. Intuitively, cement requirements are higher during the development phase of each country, during which roads, harbours, airports, urban areas, hospitals, schools, and many other infrastructures are built. Once developed, the demand of cement per capita drops significantly, as the requirement for new infrastructure is reduced to a minimum and cement is then utilised mostly for maintenance and replacement. 


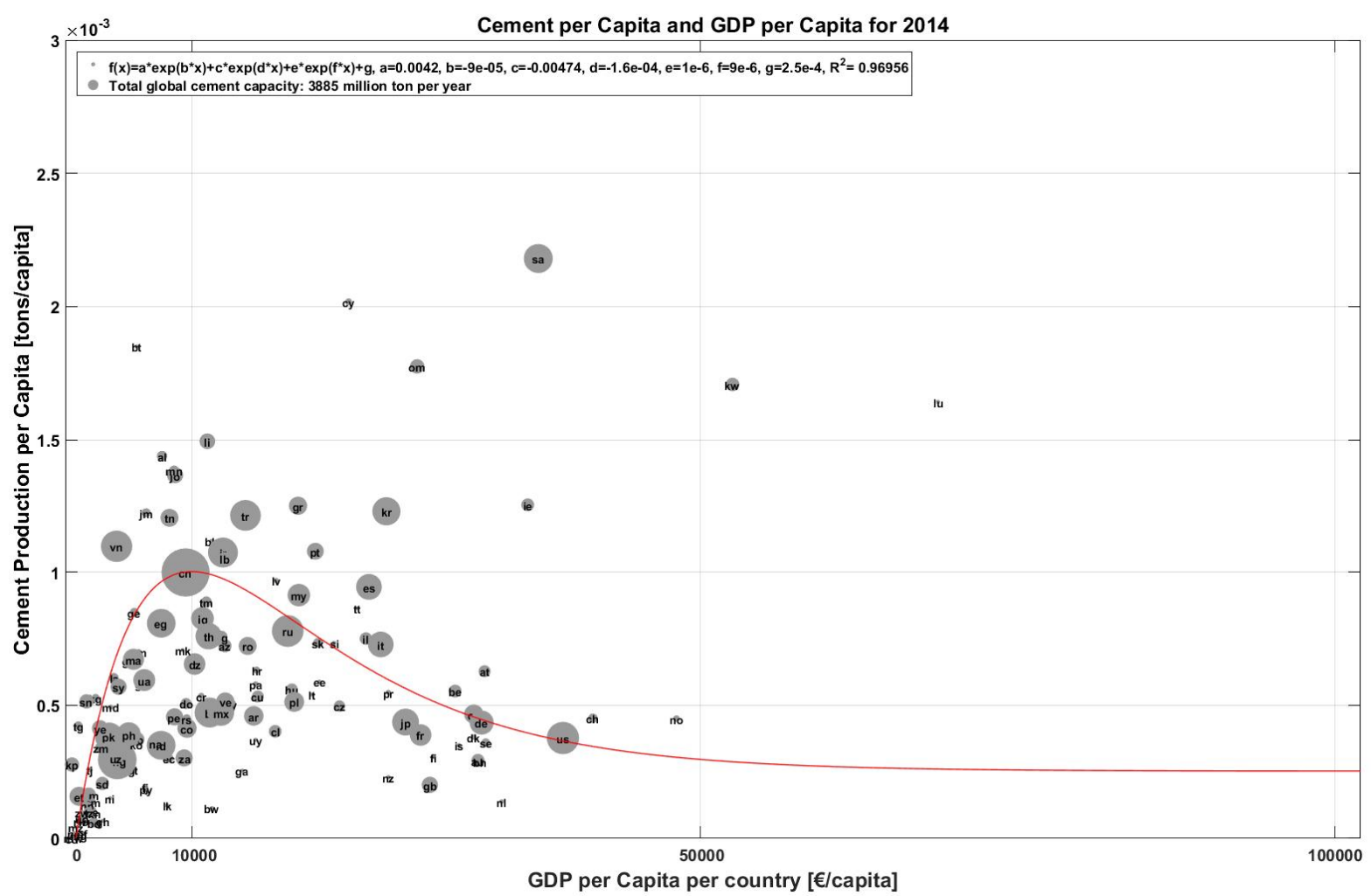

Figure 5: Distribution of cement production capacity per capita over GDP per capita globally for the year 2014. The countries are indicated by their internet country code top-level domains.

$f(x)=A \cdot e^{B \cdot x}+C \cdot e^{D \cdot x}+E \cdot e^{F \cdot x}+G$

The coefficients have been optimised through an iterative process, and the values are listed in Table 2. On the other hand, the coefficient of determination $\left(\mathrm{R}^{2}\right)$ is calculated, not only taking into account the GDP per capita and the cement production per capita, but also considering the capacity of each country as shown in Equation 2. This is done with the intention to represent beyond just the per capita values, also to take into account the very important factor that is total production, as $\mathrm{CO}_{2}$ emissions are directly proportional to this number. The variables of Equation 2 are also introduced and defined in Table 2.

$\overline{P K}=\frac{\sum_{i=1}^{n}\left(P_{i} \cdot K_{i}\right)}{n}$

$\theta=\sum_{i=1}^{n}\left(\left(P_{i} \cdot K_{i}\right)-\overline{P K}\right)^{2}$

$\beta=\sum_{i=1}^{n}\left(\left(P_{i}-Q_{i}\right) \cdot K_{i}\right)^{2}$

$R^{2}=1-\left(\frac{\beta}{\theta}\right)$

Each country analysed has GDP and population projections, as well as cement production (and therefore cement production per capita).

Table 2: Value of constants and variable definitions for Equations 1 and 2. 


\begin{tabular}{cl}
$\mathbf{A}$ & $4.2 \cdot 10^{-3}$ \\
$\mathbf{B}$ & $-9 \cdot 10^{-5}$ \\
$\mathbf{C}$ & $-4.74 \cdot 10^{-3}$ \\
$\mathbf{D}$ & $-1.6 \cdot 10^{-4}$ \\
$\mathbf{E}$ & $1 \cdot 10^{-6}$ \\
$\mathbf{F}$ & $9 \cdot 10^{-6}$ \\
$\mathbf{G}$ & $2.5 \cdot 10^{-4}$ \\
\hline Variable & Definition (Equation 2$)$ \\
$\mathbf{f}(\mathbf{x})$ & Tailored fitting function for cement/GDP per capita projection \\
$\mathbf{P}_{\mathbf{i}}$ & Cement production per capita of country $\mathrm{i}$ \\
$\mathbf{\mathbf { K } _ { \mathbf { i } }}$ & Active cement production capacity of country $\mathrm{i}$ \\
$\mathbf{Q}_{\mathbf{i}}$ & $\mathrm{f}_{(\mathrm{x})}$ value for the GDP per capita of country $\mathrm{i}$ \\
\hline $\mathbf{P K}$ & Average value of the sum from i=1 to $\mathrm{n}$ of $\mathrm{P}_{\mathrm{i}} \cdot \mathrm{K}_{\mathrm{i}}$ \\
$\mathbf{R}^{2}$ & Coefficient of determination \\
$\mathbf{n}$ & Total number of countries
\end{tabular}

Carbon and hydrogen are the main building blocks for hydrocarbons and many other chemicals. In the power-to-gas $(\mathrm{PtG})$ approach, $\mathrm{RE}$ is used to generate hydrogen by water electrolysis. In the next step, methane is produced synthetically from hydrogen and $\mathrm{CO}_{2}$ by using the Sabatier reaction in a methanation unit. With $\mathrm{CO}_{2}$ already available, the overall process can reach an efficiency of $65 \%$ based on high heating value (HHV) in 2030 [11].

In the power-to-liquids (PtL) approach, to generate longer-chained hydrocarbons, $\mathrm{H}_{2}$ and $\mathrm{CO}_{2}$ are first converted to a mixture of $\mathrm{H}_{2}$ and $\mathrm{CO}$ (known as syngas) in a reverse water-gas shift unit. In the next step, the syngas is converted to syncrude (a mixture of different hydrocarbons such as light fuel gases, naphtha, kerosene, diesel and waxes) in a Fischer-Tropsch reactor. The heavy liquids and waxes could be broken down to lighter hydrocarbons with a shorter carbon chain in a hydrocracker unit. The system could run on diesel or kerosene mode, aiming for the highest share of each (60\% diesel or $50 \%$ kerosene) in the output, according to the demand. The PtL overall efficiency could reach $54 \%$ by 2030 . In addition, there would be excess heat available from both PtG and PtL processes [11]. The bulk chemicals such as methanol can be produced in different reactors under different chemical reactions [17, 30].

\subsection{Power-to-X assumptions}

The idea or concept of applying carbon capture to the cement manufacturing process has been analysed before. Different studies compiled by Leeson et al. [22] show a range of efficiencies and techniques for carbon capture. The two main trends are amine scrubbing and calcium looping, both supported by oxy-combustion. The level of assumptions and considerations used by each of the analysed cases is different, and so are the results, reporting for processes of oxycombustion $+\mathrm{CaL}$ with efficiencies from $52 \%$ to $94 \%$. This significant level of uncertainty and the fact that technologies proposed for carbon capture are at best in pilot stage for the cement industry complicates the selection of a specific efficiency. Instead, incremental efficiencies for carbon capture will be assumed, using 60\% efficiency until 2030 and increasing to $70 \%$ and $80 \%$ for 2040 and 2050, respectively. Furthermore, taking into account that only $50 \%$ of the emissions are associated with the limestone thermal processing, rest of the emissions could be neutralised by replacing the fuel from coal and natural gas with RE-based carbon-neutral synthetic fuels, biofuels, waste, biomass or avoided by direct use of renewable electricity. The 
transportation share of the emissions can be avoided by usage of electric vehicles or running combustion vehicles with synthetic fuels or biofuels.

In order to analyse the $\mathrm{CO}_{2}$ potential for synthetic hydrocarbons four different case scenarios are defined, with the range of energy consumption presented in Table 3 and level of emissions presented in Table 4 . The emission levels per ton of cement according to the different scenarios are represented in Figure 6 and the evolution of $\mathrm{CO}_{2}$ emitted and captured as well as estimated cement production is shown in Figure 7. The efficiencies of carbon capture (excluding transportation emissions) are $60 \%$ for the calculations before 2030 , and $70 \%$ and $80 \%$ for the years 2040 and 2050, respectively. The four scenarios represent very distinct pathways, so that individual pathways can be created as a mix of the presented scenarios to also reflect different diffusion dynamics of new technologies and measures, which can be varied on a per country basis with the data provided in the Supplementary Material. The scenarios are as follows:

- Business as usual (BAU): Continuation with the current trends of coal and natural gas for fuel with a $10 \%$ share of alternative fuels (waste and biomass) at a global average, with considering the specific average $\mathrm{CO}_{2}$ emissions of every region per ton of clinker before carbon capture, according to the World Business Council for Sustainable Development (WBCSD) database [25].

- Cement sustainability initiative target (CSIt): WBCSD [25] target for $\mathrm{CO}_{2}$ emissions reduction, at $-18.7 \%$ of $\mathrm{BAU} \mathrm{CO}_{2}$ emissions per ton of clinker ( $-24 \%$ net $\mathrm{CO}_{2}$ emissions) before carbon capture. This is achieved through higher shares (up to 37\%) of alternative fuels utilised (assuming the $\mathrm{CO}_{2}$ fuel emissions presented by [31] and the waste emissions measured by [32]), and improving technology efficiency.

- Best case scenario - alternative fuels (BCSa): $\mathrm{CO}_{2}$ emissions reduction of $-42.9 \%$ of BAU per ton of clinker due to use of oxy-fuel combustion with $50 \%$ hydrogen (rounded as the share of hydrogen used in [33] and 50\% waste as fuel for thermal processing of limestone. Emissions from electricity and transportation are excluded, as they cannot be captured, but in principle could already be neutralised (e.g. through renewable energy and use of electric vehicles). It is assumed that this scenario can be achieved from 2030 onwards. The technology improvements of the CSIt scenario are also assumed.

- Best case scenario - electric (BCSe): Emissions reduction of -50\% of BAU per ton of clinker by using electricity from RE sources, and transportation emissions are neglected as in the previous scenario. Use of electricity derived from renewable sources is assumed to be used for the thermal processing of limestone [12] (with only the emissions of the raw material remaining). It is assumed that this scenario can be achieved from 2030 onwards and technology improvements of the CSIt scenario are applied. This scenario may exhibit the highest engineering challenges among the four scenarios as the process itself would change substantially, and there is not yet technology available at the commercial stage. Therefore, the assumption on energy consumption is estimated as in BCSa and CSIt, though when developed and implemented for industrial scale the technology may show different consumption. 


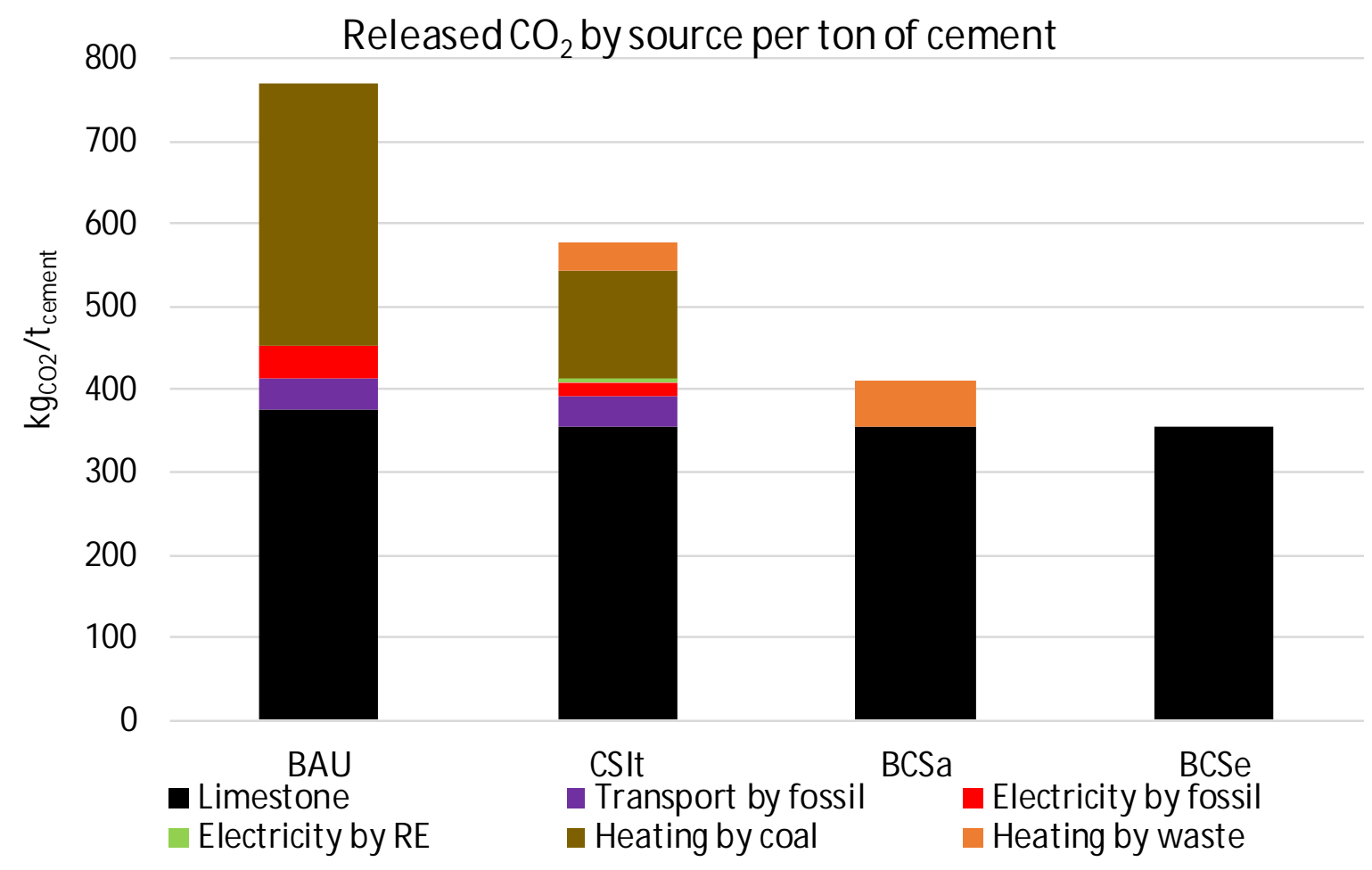

Figure 6: Emission levels by source for different scenarios.

Table 3: Estimated range of energy demand for different scenarios. Mean electricity demand for BAU is taken from [34] and range of electricity demand is taken from [35]. Range of heat energy for BAU is taken from [4]. The following ranges are assumed with the mean values between the average in BAU and the minimum for BAU, with BCSe having the most uncertainty.

\begin{tabular}{|c|c|c|c|c|c|c|}
\hline Scenario & $\begin{array}{l}\text { Min Heat } \\
\text { Energy }\end{array}$ & $\begin{array}{l}\text { Mean Heat } \\
\text { Energy }\end{array}$ & $\begin{array}{l}\text { Max Heat } \\
\text { Energy }\end{array}$ & $\begin{array}{l}\text { Min } \\
\text { Electric } \\
\text { Energy }\end{array}$ & \begin{tabular}{|l|} 
Mean \\
Electric \\
Energy \\
\end{tabular} & $\begin{array}{l}\text { Max } \\
\text { Electric } \\
\text { Energy } \\
\end{array}$ \\
\hline BAU & $707 \mathrm{kWh}$ & $919 \mathrm{kWh}$ & $1616 \mathrm{kWh}$ & $70 \mathrm{kWh}$ & $106 \mathrm{kWh}$ & $140 \mathrm{kWh}$ \\
\hline CSIt & 707 kWh & $813 \mathrm{kWh}$ & $919 \mathrm{kWh}$ & $70 \mathrm{kWh}$ & $88 \mathrm{kWh}$ & $106 \mathrm{kWh}$ \\
\hline BCSa & $707 \mathrm{kWh}$ & $813 \mathrm{kWh}$ & $919 \mathrm{kWh}$ & $70 \mathrm{kWh}$ & $88 \mathrm{kWh}$ & $106 \mathrm{kWh}$ \\
\hline BCSe & $707 \mathrm{kWh}$ & $813 \mathrm{kWh}$ & $919 \mathrm{kWh}$ & $70 \mathrm{kWh}$ & $88 \mathrm{kWh}$ & $106 \mathrm{kWh}$ \\
\hline
\end{tabular}




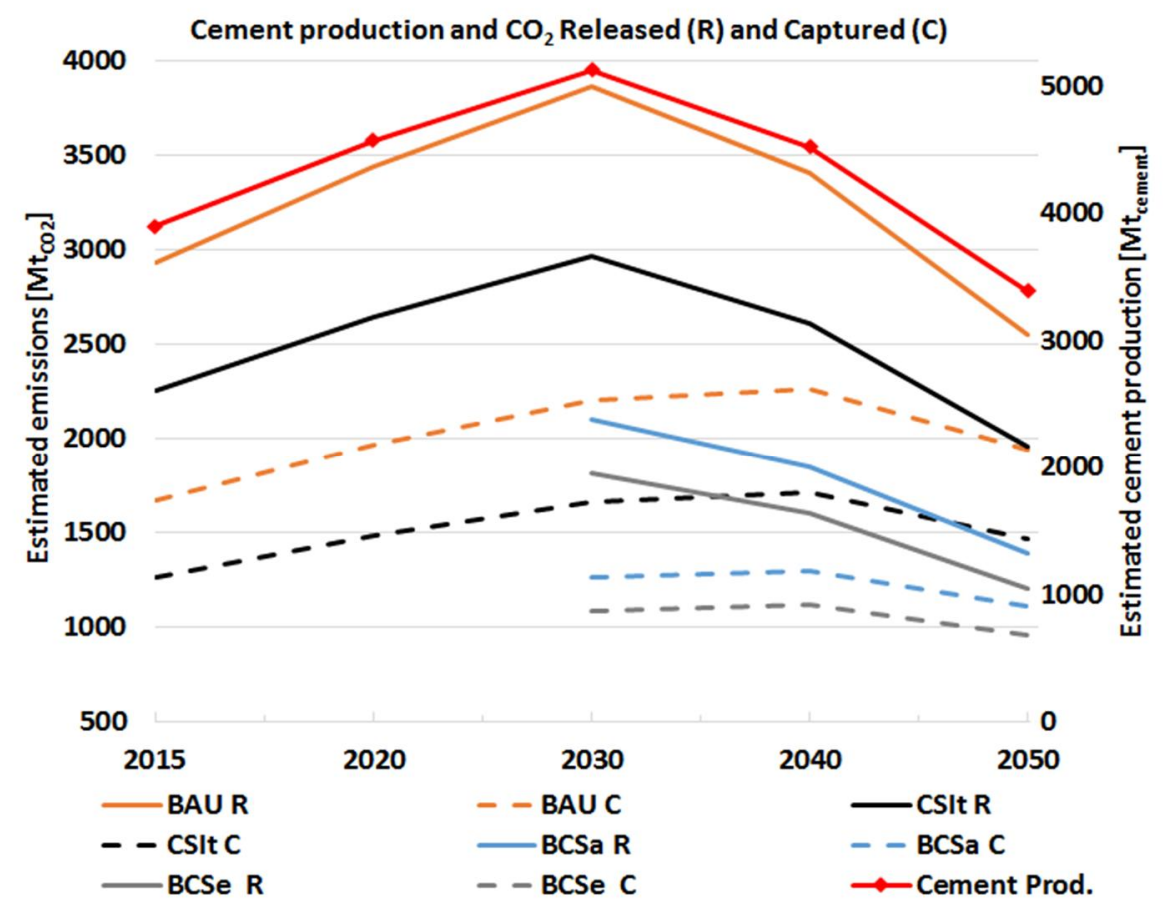

Figure 7: Timeline estimation of total global cement production (red), as well as $\mathrm{CO}_{2}$ released (R) in solid lines and captured $(\mathrm{C})$ in dashed lines respectively for every scenario.

Table 4: Estimated cement production, $\mathrm{CO}_{2}$ emissions and captured $\mathrm{CO}_{2}$ potential for the different defined scenarios. The assumptions for the potential for the captured $\mathrm{CO}_{2}$ are $60 \%$ for the years before 2030, and 70\% and $80 \%$ for 2040 and 2050 respectively in all scenarios, and $-6 \%$ clinker to cement ratio for CSIt and both BCS scenarios.

\begin{tabular}{|c|c|c|c|c|c|c|}
\hline \multicolumn{7}{|c|}{ Total estimated emissions before carbon capture [Mtco2] } \\
\hline & $\begin{array}{c}\text { Cement } \\
\text { production } \\
\text { estimated } \\
\text { [Mt] }\end{array}$ & $\mathbf{B A U}$ & CSIt & BCSa & BCSe & \\
\hline 2015 & 3896 & 2934 & 2252 & $\mathbf{n} / \mathbf{a}$ & $\mathbf{n} / \mathbf{a}$ & \\
\hline 2020 & 4569 & 3441 & 2640 & $\mathbf{n} / \mathbf{a}$ & $\mathbf{n} / \mathbf{a}$ & \\
\hline 2030 & 5124 & 3859 & 2961 & 2098 & 1814 & \\
\hline 2040 & 4517 & 3401 & 2610 & 1849 & 1599 & \\
\hline 2050 & 3387 & 2551 & 1957 & 1387 & 1199 & \\
\hline \multicolumn{7}{|c|}{$\begin{array}{c}\text { Total estimated captured } \mathrm{CO}_{2} \text { potential for Power-to-X } \\
\text { usage }\left[\mathrm{MtcO}_{2}\right]\end{array}$} \\
\hline & $\begin{array}{c}\text { Cement } \\
\text { production } \\
\text { estimated } \\
\text { [Mt] }\end{array}$ & $\mathbf{B A U}$ & CSIt & BCSa & BCSe & $\begin{array}{c}\text { Assumed } \mathrm{CO}_{2} \\
\text { capture } \\
\text { efficiency }\end{array}$ \\
\hline 2015 & 3896 & 1672 & 1263 & $\mathbf{n} / \mathbf{a}$ & $\mathbf{n} / \mathbf{a}$ & $60 \%$ \\
\hline 2020 & 4569 & 1961 & 1481 & $\mathbf{n} / \mathbf{a}$ & $\mathbf{n} / \mathbf{a}$ & $60 \%$ \\
\hline 2030 & 5124 & 2199 & 1661 & 1259 & 1088 & $60 \%$ \\
\hline 2040 & 4517 & 2262 & 1708 & 1294 & 1119 & $70 \%$ \\
\hline 2050 & 3387 & 1938 & 1464 & 1109 & 959 & $\mathbf{8 0 \%}$ \\
\hline
\end{tabular}

Considering the previously mentioned available $\mathrm{CO}_{2}$, two options are proposed for Power-to$\mathrm{X}(\mathrm{PtX})$ : synthetic natural gas $(\mathrm{SNG})$ production through Power-to-Gas $(\mathrm{PtG})$ and synthetic liquid hydrocarbons through Power-to-Liquids (PtL). The $\mathrm{CO}_{2}$ would be provided by carbon 
capture technologies. The two leading technologies for carbon capture are calcium looping $(\mathrm{CaL})$ and amine scrubbing [36], both fairly well developed for application in energy conversion systems.

CaL consists of two interconnected fluidised bed reactors, of which in the first (carbonation reactor) flue gas is treated with a calcium-based sorbent (which can be lime itself from the cement processing cycle) at temperatures in the range of $650-850{ }^{\circ} \mathrm{C}$ and atmospheric pressure [37]. The formed particles of $\mathrm{CaCO}_{3}$ are then separated and sent to the second reactor (calcination reactor), an oxy-fired fluidised bed at over $900^{\circ} \mathrm{C}$ that produces a close-to-pure $\mathrm{CO}_{2}$ suitable for storage and lime $(\mathrm{CaO})$ for recycling into the carbonator [36, 37]. Over several cycles, the lime loses reactivity and it becomes part of the clinker output, while new limestone for processing can refresh the reactive lime into the reaction. The main advantage of this technology is that flue gases can be treated at a high temperature and low pressure that is already produced from the cement processing process. However, there is still no research on how the unreactive lime affects the characteristics of the clinker or cement, and how it limits the capacity of concrete to later absorb $\mathrm{CO}_{2}$.

Amine scrubbing, which is widely used in the chemical sector $[36,37]$, consists of chemical gas-liquid absorption using alkanolamines. The flue gas is cooled down and then treated by exposing it to contact with an amine liquid solution in the absorption stack. Afterwards, the $\mathrm{CO}_{2}$-rich solvent is transferred to another stack where it is treated with heat for desorption, separating the $\mathrm{CO}_{2}$ for condensing and storage, and the solvent for recycling back to the absorption column [36]. One of the main disadvantages of amine scrubbing is the need for cooling of the flue gasses before the treating and the additional heating required for the desorption process. It should be noted that, though both carbon capture techniques are fairly developed, they are not efficiently coupled to the cement processing system because of the differences of the cement processing in comparison with other point source carbon emitters, such as power plants.

\section{Results}

\subsection{Current state}

As shown in Figure 5, China is positioned at the peak of the projection function. Even though the Chinese production and demand from 2010 to 2013 was still increasing dramatically, in the past few years it has halted and even decreased, due to basic infrastructure being mostly deployed, resulting in under-utilisation and over-capacities [38]. Though the world's main producing and consuming country seems to have already peaked, still a large number of countries remain in the underdeveloped zone of less than 10,000 € per capita, which means that the global cement production is expected to grow. At the same time some Middle Eastern countries such as Saudi Arabia, Qatar, Kuwait, Oman, etc. show an "inflated" consumption of cement, mostly because of the instantly generated wealth from the oil and gas industry boom in a previously heavily underdeveloped area.

Due to the high global cement demand, a $\mathrm{CO}_{2}$ emissions mitigation strategy should be implemented in order to achieve greater sustainability, much more than what is already planned to be implemented [25]. Several strategies are available for cement GHG emissions reduction. From relatively simple ones like using renewable electricity and waste as alternative fuel $[3,5$, 39, 40], CCS [41], and even CCU for producing carbon nanotubes [42]. Usón et al. [40] provided an overview on alternative fuels usage and mentioned Norway, Germany and Austria 
reaching an alternative fuel ratio in cement production of $60.0 \%, 62.0 \%$ and $63.1 \%$, whereas the Netherlands achieved $83 \%$ replacement of fossil fuels with waste materials. Usón et al. also report on the relative $\mathrm{H}_{2}$ share of syngas from various wastes, such as $42.7 \%$ (municipal solid waste), $45.5 \%$ (biomass) and $51.5 \%$ (tyres).

Cao et al. [43] further reinforced the finding of GDP and infrastructure development dependency of cement per capita demand. For this reason developing countries (India, Philippines, China, Mexico, Vietnam, etc.) experience higher per capita demand of cement than developed countries (Norway, United States, Netherlands, Denmark, Japan, etc.) as shown in Figure 5.

\subsection{Future projections}

Based on the GDP and infrastructure dependency premise, Figure 8 shows a projection of the global cement production capacity demand by country for 2020, 2030, 2040, 2050. The GDP projection is taken from Toktarova et al. [44]. The cement production capacity per capita and total capacities are adjusted to the growing GDP, as the circles of each country approach the steady state of the projection line.

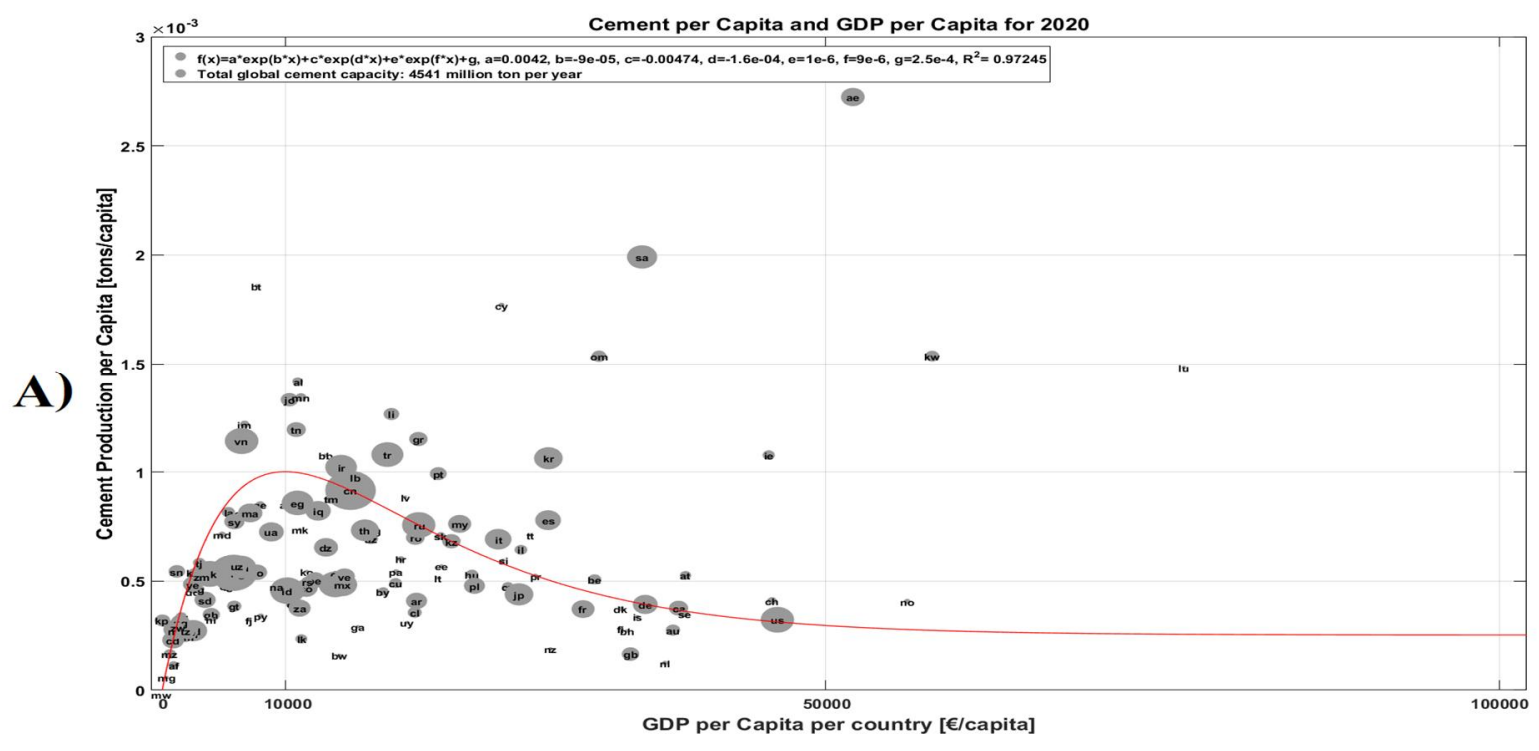



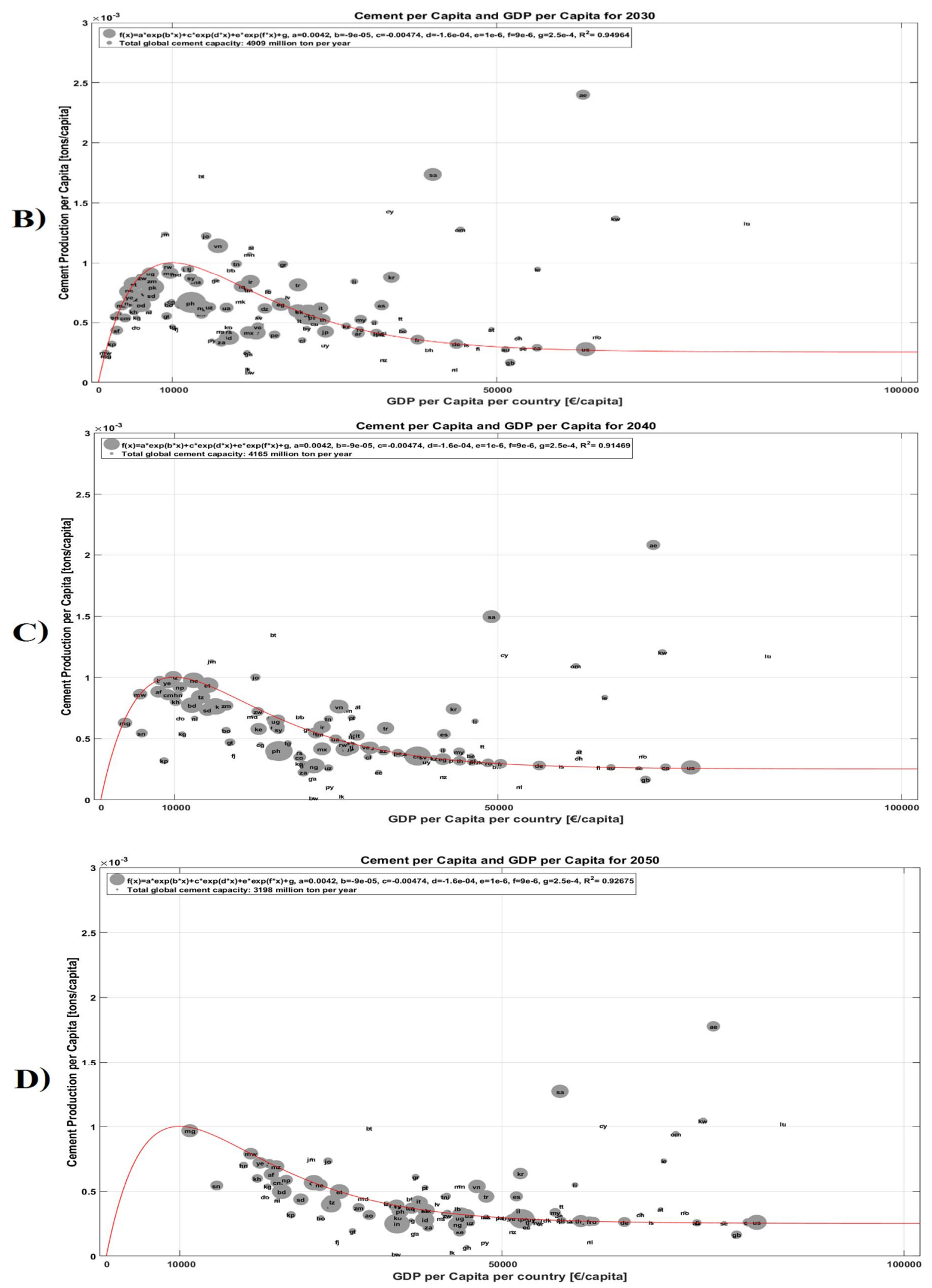

Figure 8: Distribution of cement per capita over GDP per capita globally for 2020 (A), 2030 (B), 2040 (C) and 2050 (D).

As shown in Figure 8, due to the expected development of Asian, African and Latin American countries (and despite China reducing steadily its production) the global cement production 
capacity demand is expected to increase from $3885 \mathrm{Mt}$ in 2014 to $4541 \mathrm{Mt}$ in 2020, and further to $4909 \mathrm{Mt}$ in 2030. The global production is then expected to decrease to $4165 \mathrm{Mt}$ in 2040 and $3198 \mathrm{Mt}$ in 2050, reaching finally below current levels of demand.

\subsection{Power-to-X potential}

By 2050, and according to the calculations, the potential of captured $\mathrm{CO}_{2}$ for $\mathrm{PtX}$ use would be distributed globally as shown in Figure 9. Using the aforementioned methods for $\mathrm{CO}_{2}$ utilisation, the potential for fuel production based on HHV and the additional demand of electricity and hydrogen to generate the desired fuels are displayed in Table 5. Most of the additional electricity demand is for hydrogen production through electrolysis. It can be noticed that (due to projected global cement demand) the peak potential for PtX production is reached in 2040 for all scenarios, (at a maximum of about $7355 \mathrm{TWh}_{\text {th }}$ or $12723 \mathrm{TWh}_{\text {th }}$ of liquid hydrocarbons and SNG respectively for BAU, $5555 \mathrm{TWh}_{\text {th }}$ or $9599 \mathrm{TWh}_{\text {th }}$ for CSIt, 4209 $\mathrm{TWh}_{\text {th }}$ or $7288 \mathrm{TWh}_{\text {th }}$ for BCSa, and $3639 \mathrm{TWh}_{\text {th }}$ or $6298 \mathrm{TWh}_{\text {th }}$ for BCSe).

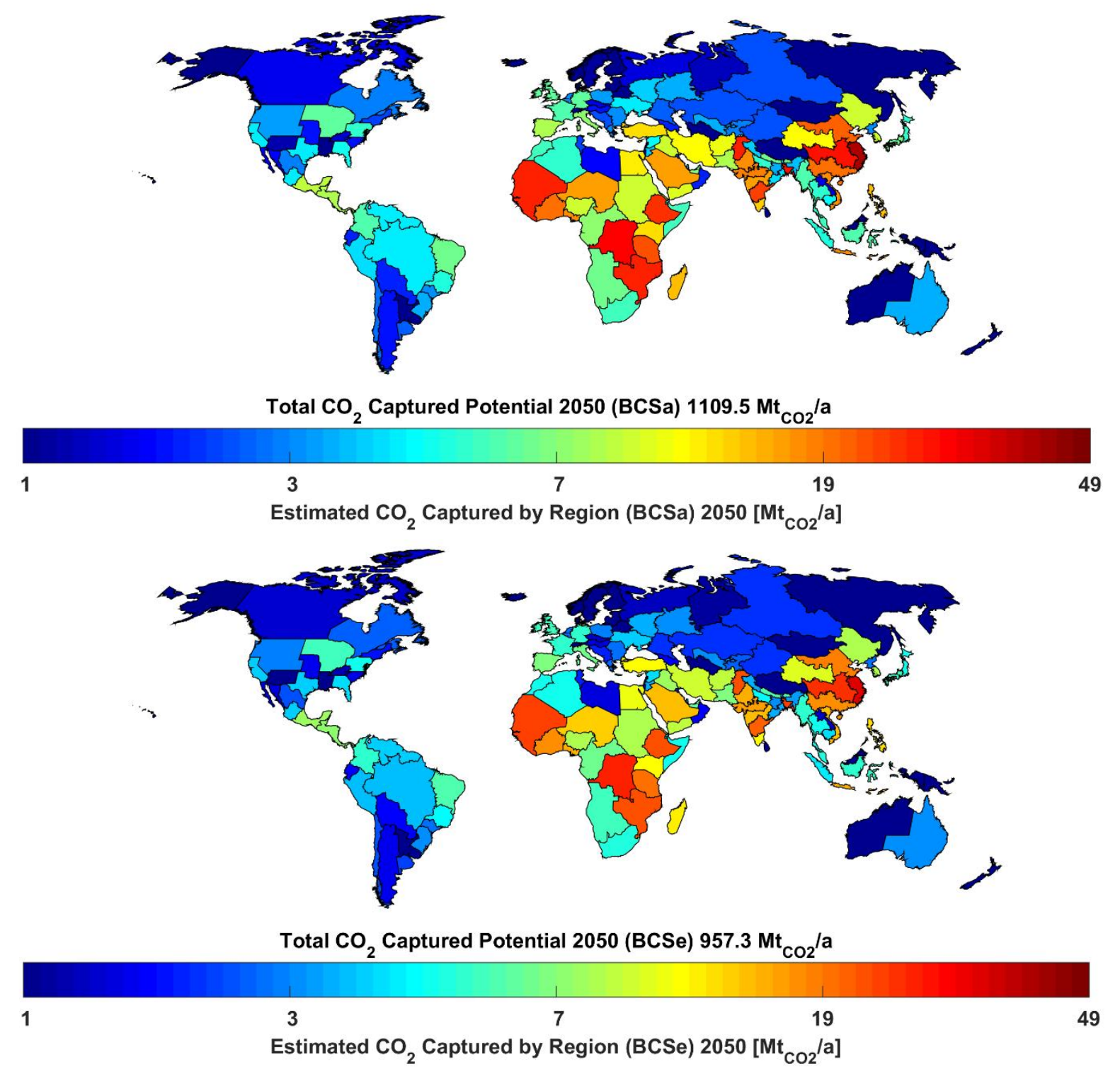

Figure 9: Estimated captured $\mathrm{CO}_{2}$ by region by 2050 according to BCSa (top) and BCSe (bottom). 
Table 5: Estimated synthetic fuel production potential based on $\mathrm{CO}_{2}$ emissions for the different defined scenarios for a carbon capture ratio of $60 \%$ for the years before 2030, and $70 \%$ and $80 \%$ for 2040 and 2050 respectively in all cases. The input electricity is mainly used for the hydrogen production.

\begin{tabular}{|c|c|c|c|c|c|c|c|c|c|c|}
\hline \multirow{2}{*}{$\begin{array}{c}\text { Input } \\
\text { Output }\end{array}$} & \multirow[b]{2}{*}{ year } & \multicolumn{4}{|c|}{ PtL } & \multicolumn{4}{|c|}{ PtG } & \multirow{2}{*}{$\begin{array}{l}\text { Difference to } \\
2015 \text { in \% }\end{array}$} \\
\hline & & $\mathrm{MtCO}_{\mathrm{CO}}$ & $\mathrm{H}_{2} \mathrm{TWh}$ & TWh $_{\text {e }}$ & TWh $_{\text {th }}$ & $\mathrm{MtCO}_{2}$ & $\mathrm{H}_{2} \mathrm{TWh}$ & $\mathbf{T W h}_{\mathrm{e}}$ & TWh $_{\text {th }}$ & \\
\hline \multirow{5}{*}{$\mathbf{B A U}$} & 2015 & 1672 & 8524 & 10515 & 5438 & 1672 & 11929 & 14366 & 9397 & $0 \%$ \\
\hline & 2020 & 1961 & 9997 & 12332 & 6377 & 1961 & 13989 & 16847 & 11020 & $15 \%$ \\
\hline & 2030 & 2199 & 11211 & 13830 & 7152 & 2199 & 15689 & 18893 & 12358 & $24 \%$ \\
\hline & 2040 & 2262 & 11530 & 14223 & 7355 & 2262 & 16151 & 19451 & 12723 & $26 \%$ \\
\hline & 2050 & 1938 & 9881 & 12189 & 6303 & 1938 & 13827 & 16652 & 10892 & $14 \%$ \\
\hline \multirow{5}{*}{ CSIt } & 2015 & 1263 & 6437 & 7941 & 4107 & 1263 & 9009 & 10850 & 7097 & $0 \%$ \\
\hline & 2020 & 1481 & 7549 & 9313 & 4816 & 1481 & 10565 & 12724 & 8323 & $15 \%$ \\
\hline & 2030 & 1661 & 8466 & 10444 & 5401 & 1661 & 11849 & 14269 & 9334 & $24 \%$ \\
\hline & 2040 & 1708 & 8707 & 10741 & 5555 & 1708 & 12186 & 14675 & 9599 & $26 \%$ \\
\hline & 2050 & 1464 & 7462 & 9205 & 4760 & 1464 & 10441 & 12574 & 8225 & $14 \%$ \\
\hline \multirow{5}{*}{ BCSa } & 2015 & $\mathbf{n} / \mathbf{a}$ & $\mathbf{n} / \mathbf{a}$ & $\mathbf{n} / \mathbf{a}$ & $\mathbf{n} / \mathbf{a}$ & $\mathbf{n} / \mathbf{a}$ & $\mathbf{n} / \mathbf{a}$ & $\mathbf{n} / \mathbf{a}$ & $\mathbf{n} / \mathbf{a}$ & ence to \\
\hline & 2020 & $\mathbf{n} / \mathbf{a}$ & $\mathbf{n} / \mathbf{a}$ & $\mathbf{n} / \mathbf{a}$ & $\mathbf{n} / \mathbf{a}$ & $\mathbf{n} / \mathbf{a}$ & $\mathbf{n} / \mathbf{a}$ & $\mathbf{n} / \mathbf{a}$ & $\mathbf{n} / \mathbf{a}$ & \\
\hline & 2030 & 1259 & 6416 & 7914 & 4093 & 1259 & 8996 & 10834 & 7087 & $0 \%$ \\
\hline & 2040 & 1294 & 6598 & 8140 & 4209 & 1294 & 9252 & 11142 & 7288 & $3 \%$ \\
\hline & 2050 & 1109 & 5654 & 6975 & 3607 & 1109 & 7929 & 9548 & 6246 & $-13 \%$ \\
\hline \multirow{5}{*}{ BCSe } & 2015 & $\mathbf{n} / \mathbf{a}$ & $\mathbf{n} / \mathbf{a}$ & $\mathbf{n} / \mathbf{a}$ & $\mathbf{n} / \mathbf{a}$ & $\mathbf{n} / \mathbf{a}$ & $\mathbf{n} / \mathbf{a}$ & $\mathbf{n} / \mathbf{a}$ & $\mathbf{n} / \mathbf{a}$ & Difference to \\
\hline & 2020 & $\mathbf{n} / \mathbf{a}$ & $\mathbf{n} / \mathbf{a}$ & $\mathbf{n} / \mathbf{a}$ & $\mathbf{n} / \mathbf{a}$ & $\mathbf{n} / \mathbf{a}$ & $\mathbf{n} / \mathbf{a}$ & $\mathbf{n} / \mathbf{a}$ & $\mathbf{n} / \mathbf{a}$ & \\
\hline & 2030 & 1088 & 5546 & 6842 & 3538 & 1088 & 7753 & 9337 & 6107 & $0 \%$ \\
\hline & 2040 & 1119 & 5704 & 7037 & 3639 & 1119 & 7995 & 9628 & 6298 & $3 \%$ \\
\hline & 2050 & 959 & 4888 & 6030 & 3118 & 959 & 6841 & 8238 & 5389 & $-13 \%$ \\
\hline
\end{tabular}

The distribution of the synthetic fuels production potential across the global regions is presented in Table 6 . Though the global synthetic fuels production potential (shown in Table 5) peaks in 2040, the tendencies for every individual region differs broadly. A steep constant decrease is projected for Northeast Asia and a slight decrease for Europe, regions which already have deployed most of the required infrastructure. SAARC (South Asian Association for Regional Cooperation) and Sub-Saharan Africa experience a well-defined 'rise-and-fall' tendency, peaking in 2030 and 2040 respectively. The rest of the regions go through a rather flat development over the years, with small variations in potential from decade to decade, increasing or decreasing by small amounts.

Six out of the nine regions (excluding Europe, Eurasia and Northeast Asia) are projected to have a higher CCU-PtX potential (due to cement demand) than in 2015. From these regions, only SAARC and Sub-Saharan Africa have a significant increase in potential to 2015 levels for a factor of two and eight respectively. On the contrary, Northeast Asian potential drops by around $50 \%$, while Europe and Eurasia drop by roughly $30 \%$ and $40 \%$ respectively. The rest of the world regions experience almost insignificant increase or decrease in potential from an absolute value point of view, but not more than $+/-20 \%$ in relative values. Overall, the global potential of PtX increases by $16 \%$ by 2050 compared to 2015 values, mostly due to the assumed increase in carbon capture efficiency as the global cement production is expected to decrease.

Table 6: Estimated synthetic fuel production potential in regional distribution for all scenarios. 


\begin{tabular}{|c|c|c|c|c|c|c|c|c|c|c|}
\hline Region & \multicolumn{5}{|c|}{ PtL $\left[T_{W h} h_{t h}\right]$} & \multicolumn{5}{|c|}{$P t G\left[T W h_{t h}\right]$} \\
\hline BAU & 2015 & 2020 & 2030 & 2040 & 2050 & 2015 & 2020 & 2030 & 2040 & 2050 \\
\hline Europe & 583 & 550 & 464 & 435 & 414 & 1009 & 951 & 802 & 751 & 715 \\
\hline Eurasia & 225 & 231 & 213 & 165 & 142 & 390 & 399 & 368 & 285 & 245 \\
\hline MENA & 590 & 636 & 647 & 635 & 596 & 1020 & 1100 & 1119 & 1097 & 1030 \\
\hline $\begin{array}{l}\text { Sub-Saharan } \\
\text { Africa }\end{array}$ & 209 & 505 & 1336 & 2014 & 1688 & 362 & 873 & 2311 & 3482 & 2918 \\
\hline SAARC & 658 & 1237 & 1845 & 1776 & 1218 & 1138 & 2139 & 3191 & 3070 & 2106 \\
\hline Northeast Asia & 2122 & 2021 & 1443 & 1158 & 1049 & 3668 & 3493 & 2495 & 2002 & 1814 \\
\hline Southeast Asia & 462 & 583 & 630 & 555 & 542 & 799 & 1008 & 1090 & 960 & 938 \\
\hline North America & 273 & 261 & 242 & 289 & 327 & 472 & 451 & 418 & 499 & 566 \\
\hline South America & 296 & 331 & 312 & 323 & 316 & 511 & 572 & 540 & 559 & 546 \\
\hline \multirow[t]{2}{*}{ Total Global } & 5438 & 6377 & 7152 & 7355 & 6303 & 9397 & 11020 & 12358 & 12723 & 10892 \\
\hline & \multicolumn{5}{|c|}{ PtL $\left[T_{W h} h_{t h}\right]$} & \multicolumn{5}{|c|}{ PtG $\left[T_{W h} h_{t h}\right]$} \\
\hline CSIt & 2015 & 2020 & 2030 & 2040 & 2050 & 2015 & 2020 & 2030 & 2040 & 2050 \\
\hline Europe & 441 & 415 & 350 & 328 & 312 & 762 & 718 & 606 & 567 & 540 \\
\hline Eurasia & 170 & 174 & 161 & 124 & 107 & 294 & 302 & 278 & 215 & 185 \\
\hline MENA & 445 & 480 & 489 & 479 & 450 & 770 & 831 & 845 & 828 & 778 \\
\hline $\begin{array}{l}\text { Sub-Saharan } \\
\text { Africa }\end{array}$ & 158 & 381 & 1009 & 1519 & 1275 & 273 & 659 & 1745 & 2627 & 2204 \\
\hline SAARC & 497 & 934 & 1394 & 1340 & 920 & 859 & 1615 & 2410 & 2316 & 1590 \\
\hline Northeast Asia & 1602 & 1526 & 1090 & 874 & 792 & 2771 & 2638 & 1884 & 1510 & 1370 \\
\hline Southeast Asia & 349 & 440 & 476 & 419 & 410 & 604 & 762 & 823 & 724 & 708 \\
\hline North America & 206 & 197 & 183 & 218 & 247 & 357 & 341 & 316 & 377 & 427 \\
\hline South America & 223 & 250 & 236 & 244 & 238 & 386 & 432 & 408 & 422 & 412 \\
\hline \multirow[t]{2}{*}{ Total Global } & 4107 & 4816 & 5401 & 5555 & 4760 & 7097 & 8323 & 9334 & 9599 & 8225 \\
\hline & \multicolumn{5}{|c|}{ PtL $\left[T_{W h} h_{t h}\right]$} & \multicolumn{5}{|c|}{$P t G\left[T_{W h} h_{t h}\right]$} \\
\hline BCSa & 2015 & 2020 & 2030 & 2040 & 2050 & 2015 & 2020 & 2030 & 2040 & 2050 \\
\hline Europe & $\mathbf{n} / \mathbf{a}$ & $\mathbf{n} / \mathbf{a}$ & 266 & 249 & 237 & $\mathbf{n} / \mathbf{a}$ & $\mathbf{n} / \mathbf{a}$ & 460 & 430 & 410 \\
\hline Eurasia & $\mathbf{n} / \mathbf{a}$ & $\mathbf{n} / \mathbf{a}$ & 122 & 94 & 81 & $\mathbf{n} / \mathbf{a}$ & $\mathbf{n} / \mathbf{a}$ & 211 & 163 & 141 \\
\hline MENA & $\mathbf{n} / \mathbf{a}$ & $\mathbf{n} / \mathbf{a}$ & 371 & 364 & 342 & $\mathbf{n} / \mathbf{a}$ & $\mathbf{n} / \mathbf{a}$ & 642 & 629 & 591 \\
\hline $\begin{array}{l}\text { Sub-Saharan } \\
\text { Africa }\end{array}$ & $\mathbf{n} / \mathbf{a}$ & $\mathbf{n} / \mathbf{a}$ & 766 & 1154 & 968 & $\mathbf{n} / \mathbf{a}$ & $\mathbf{n} / \mathbf{a}$ & 1325 & 1995 & 1673 \\
\hline
\end{tabular}




\begin{tabular}{|c|c|c|c|c|c|c|c|c|c|c|}
\hline SAARC & $\mathbf{n} / \mathbf{a}$ & $\mathbf{n} / \mathbf{a}$ & 1058 & 1017 & 698 & $\mathbf{n} / \mathbf{a}$ & $\mathbf{n} / \mathbf{a}$ & 1830 & 1759 & 1208 \\
\hline Northeast Asia & $\mathbf{n} / \mathbf{a}$ & $\mathbf{n} / \mathbf{a}$ & 827 & 663 & 602 & $\mathbf{n} / \mathbf{a}$ & $\mathbf{n} / \mathbf{a}$ & 1431 & 1147 & 1040 \\
\hline Southeast Asia & $\mathbf{n} / \mathbf{a}$ & $\mathbf{n} / \mathbf{a}$ & 361 & 318 & 311 & $\mathbf{n} / \mathbf{a}$ & $\mathbf{n} / \mathbf{a}$ & 625 & 550 & 538 \\
\hline North America & $\mathbf{n} / \mathbf{a}$ & $\mathbf{n} / \mathbf{a}$ & 139 & 165 & 188 & $\mathbf{n} / \mathbf{a}$ & $\mathbf{n} / \mathbf{a}$ & 240 & 286 & 324 \\
\hline South America & $\mathbf{n} / \mathbf{a}$ & $\mathbf{n} / \mathbf{a}$ & 179 & 185 & 181 & $\mathbf{n} / \mathbf{a}$ & $\mathbf{n} / \mathbf{a}$ & 309 & 320 & 313 \\
\hline \multirow[t]{2}{*}{ Total Global } & $\mathbf{n} / \mathbf{a}$ & $\mathbf{n} / \mathbf{a}$ & 4093 & 4209 & 3607 & $\mathbf{n} / \mathbf{a}$ & $\mathbf{n} / \mathbf{a}$ & 7087 & 7288 & 6246 \\
\hline & \multicolumn{5}{|c|}{ PtL $\left[T_{W h} h_{t h}\right]$} & \multicolumn{5}{|c|}{ PtG $\left[T_{W h} h_{t h}\right]$} \\
\hline BCSe & 2015 & 2020 & 2030 & 2040 & 2050 & 2015 & 2020 & 2030 & 2040 & 2050 \\
\hline Europe & $\mathbf{n} / \mathbf{a}$ & $\mathbf{n} / \mathbf{a}$ & 229 & 215 & 205 & $\mathbf{n} / \mathbf{a}$ & $\mathbf{n} / \mathbf{a}$ & 396 & 372 & 354 \\
\hline Eurasia & $\mathbf{n} / \mathbf{a}$ & $\mathbf{n} / \mathbf{a}$ & 105 & 82 & 70 & $\mathbf{n} / \mathbf{a}$ & $\mathbf{n} / \mathbf{a}$ & 182 & 141 & 121 \\
\hline MENA & $\mathbf{n} / \mathbf{a}$ & $\mathbf{n} / \mathbf{a}$ & 320 & 314 & 295 & $\mathbf{n} / \mathbf{a}$ & $\mathbf{n} / \mathbf{a}$ & 553 & 543 & 510 \\
\hline $\begin{array}{l}\text { Sub-Saharan } \\
\text { Africa } \\
\end{array}$ & $\mathbf{n} / \mathbf{a}$ & $\mathbf{n} / \mathbf{a}$ & 660 & 997 & 835 & $\mathbf{n} / \mathbf{a}$ & $\mathbf{n} / \mathbf{a}$ & 1142 & 1724 & 1444 \\
\hline SAARC & $\mathbf{n} / \mathbf{a}$ & $\mathbf{n} / \mathbf{a}$ & 912 & 879 & 603 & $\mathbf{n} / \mathbf{a}$ & $\mathbf{n} / \mathbf{a}$ & 1577 & 1520 & 1042 \\
\hline Northeast Asia & $\mathbf{n} / \mathbf{a}$ & $\mathbf{n} / \mathbf{a}$ & 713 & 573 & 519 & $\mathbf{n} / \mathbf{a}$ & $\mathbf{n} / \mathbf{a}$ & 1233 & 991 & 897 \\
\hline Southeast Asia & $\mathbf{n} / \mathbf{a}$ & $\mathbf{n} / \mathbf{a}$ & 312 & 275 & 268 & $\mathbf{n} / \mathbf{a}$ & $\mathbf{n} / \mathbf{a}$ & 539 & 475 & 464 \\
\hline North America & $\mathbf{n} / \mathbf{a}$ & $\mathbf{n} / \mathbf{a}$ & 119 & 143 & 162 & $\mathbf{n} / \mathbf{a}$ & $\mathbf{n} / \mathbf{a}$ & 207 & 247 & 280 \\
\hline South America & $\mathbf{n} / \mathbf{a}$ & $\mathbf{n} / \mathbf{a}$ & 154 & 160 & 156 & $\mathbf{n} / \mathbf{a}$ & $\mathbf{n} / \mathbf{a}$ & 267 & 277 & 270 \\
\hline Total Global & $\mathbf{n} / \mathbf{a}$ & $\mathbf{n} / \mathbf{a}$ & 3538 & 3639 & 3118 & $\mathbf{n} / \mathbf{a}$ & $\mathbf{n} / \mathbf{a}$ & 6107 & 6298 & 5389 \\
\hline
\end{tabular}

\section{Discussion}

Replacing cement and concrete by alternative substances or materials, like magnesium based concretes [16], has not yet been commercially developed or thoroughly tested and cannot realistically be considered to eliminate the emissions from cement production. Therefore, because half of the cement related GHG emissions originate directly from the limestone, CCU appears to be so far the only viable option to at least mitigate the GHG emissions in cement production. It would only reduce final GHG emissions if fossil fuels were substituted, which will be not anymore possible after the full ban of fossil fuels, which is a clear consequence of the Paris Agreement. Zhou et al. [41] pointed out, though in concept carbon capture is applicable to cement processing facilities, it is not yet widely used or even commercially available. Further development and demonstration on this topic is still required, but should be eventually accomplished. Also, for the BCSa and BCSe scenarios electricity from a fully renewable energy based system is assumed. While this is in principle possible $[10,11,15]$ the evolution of the global energy system is still not certain. 
A new strategy for cement CCU has been presented, and the regional and global potential from $\mathrm{PtX}$ has been shown. Different demands for the captured $\mathrm{CO}_{2}$ may balance the supply: rather passive applications such as enchantment of greenhouse horticulture [45] or concrete curation [46], to rather complex techniques like carbon nanotubes synthesis [41], liquid and gaseous hydrocarbon generation [11, 47], plastics [48] and a wide range of usable chemicals [17, 49, 30] and other applications such as mineral carbonation [35], etc. Furthermore, it could also be expected that new technologies and uses for captured $\mathrm{CO}_{2}$ will be developed over time. Nevertheless, the main demand sectors by volume are most likely to be synthetic fuels (liquid and gaseous) and chemicals.

In addition, the actual impact of synthetic fuels on the overall emissions of the cement industry could be discussed. Are $\mathrm{CO}_{2}$ emissions avoided or just postponed? Converting the captured $\mathrm{CO}_{2}$ into an energy carrier for later use eventually releases the captured carbon. However, synthetic fuels from captured carbon not only replace directly the emissions from the utilisation of fossil derived fuels that would have been used otherwise, but also completely avoid the emissions associated with the extraction and refining of fossil fuels. In literature, there are discussed three main techniques for carbon capture from cement and respective mitigation, which are post-combustion scrubbing CCS, oxy-combustion CCS and calcium looping plus oxy-combustion $[22,50,51]$. The carbon capture efficiencies assumed in the presented work are within the boundaries of $60 \%$ efficiency set by [52] and the $70 \%$ assumption made by [53], and the maximum efficiency of $94 \%$ reported by [22]. Efficiency for carbon capture from cement can be rather controversial, since as pointed out by [54], carbon capture has so far been applied only in one case (and reference is not available for the case). Efficiencies up to 94\% have been estimated [55], but in research with such high reported efficiencies the assumptions are often questionable or important factors, such as fuel derived emissions, additional materials derived emissions, etc. are left out. The carbon capture efficiencies are assumed as $60 \% / 70 \% /$ $80 \%$ for before 2030/2040/ 2050 respectively, as carbon capture becomes an integral part of the cement making process, the whole process could be better adapted to CCU.

Therefore, still after carbon capture, $40 \%, 30 \%$ and $20 \%$ of the raw material derived emissions would be directly released before 2030, 2040 and 2050 respectively. However, up to $43 \%$ of the raw material derived emissions (or around $21 \%$ of the current total emissions over an 83 years period $[16,56])$ is eventually absorbed by the concrete over its operational lifetime. The remaining $60 \%$ of the limestone-derived $\mathrm{CO}_{2}$, after being captured and utilised in hydrocarbons production (potentially displacing fossil-originated $\mathrm{CO}_{2}$ emissions), would be eventually emitted to the atmosphere, but still the total emissions from the cement process would be reduced by $70 \%$ compared to the BAU scenario. Over time, as carbon capture becomes an integral part of the cement production process, it is expected that adaptations can be made to significantly increase the efficiency of carbon capture, or even new better technologies could be developed.

Carbon capture (CC) from cement mills is in competition with $\mathrm{CO}_{2}$ direct air capture (DAC) [57, 58]. A cheaper source of $\mathrm{CO}_{2}$ would result in lower synthetic fuels production costs. The projected final costs for both technologies shows a great variance in literature. However, due to higher concentration of $\mathrm{CO}_{2}$ in flue gases, the carbon capture process at cement mills is most likely lower in cost than the major alternative $\mathrm{CO}_{2}$ direct air capture, which in turn can reduce the synthetic fuel production cost.

Carbon capture from cement mills, depending on the technology, increases the energy consumption by $0.3-1.4 \mathrm{MWh}$ per ton of captured $\mathrm{CO}_{2}$, and a cost of $13-124 €$ per ton of 
captured $\mathrm{CO}_{2}$ [51]. Oxy-combustion with calcium looping is considered as one of the cheapest options. In a cement mill with carbon capture coupled to PtX, oxy-combustion technologies would benefit from the excess oxygen produced in the electrolyser unit required for the PtX processes. The oxy-fuel combustion needs less fuel, as the heat loss related to nitrogen heating would be avoided. Avoiding nitrogen would decrease the volume of flue gases, which would also lower cost of the plant due to smaller flue gas facilities. In addition, CC cost would also decrease because of a smaller volume of flue gases with a higher density of $\mathrm{CO}_{2}$.

On the other hand, the reported costs for DAC are relatively higher, in the range of 150 to 300 $€$ per ton [59-64] (the amounts reported originally in USD are converted to $€$ at a $1 €$ to 1.33 USD conversion rate, for the purpose of this work). Climeworks, as a forerunner in this field, expects to reduce the costs to $75 €$ per ton for large-scale DAC farms [63]. Moreover, some literature suggests costs below that, down to $45 €$ per ton $[65,66]$ or even lower to $40-60$ $€ / t_{\mathrm{CO} 2}$ by 2050 [58], which could be confirmed for the Maghreb region in the first hourly modelling of $\mathrm{CO}_{2}$ capture [11]. The current consensus on the price of cement is $26 €$ per ton of cement for dry kiln process with precalciner [50]. In addition, the impact of energy cost would be minimised for a DAC unit with low temperature energy demand coupled by PtX plants, as it could receive about $87 \%$ of its energy demand from excess heat of synthesis units. Thus, higher electricity prices would not have a major impact on DAC.

Although cement $\mathrm{CC}$ could be lower in cost than $\mathrm{CO}_{2} \mathrm{DAC}$, other factors for cheaper synthetic fuel production should be also taken into account. Access to relatively low-cost electricity with high full load hours (FLh) at the location of cement mills is crucial for low-cost hydrogen generation, as the other feedstock for fuel production happens to have a bigger impact on the final costs of synthetic fuels. As an example, for an electricity cost of $24 € / \mathrm{MWh}$ and $6480 \mathrm{FLh}$ and a $\mathrm{CO}_{2}$ cost of 20 or $42 € /$ ton in 2030, SNG could be generated for a final cost of 53 or 57 $€ / M W h$, respectively. However, such a good levelised cost of electricity (LCOE) and FLh may not be achievable in most parts of the world. An LCOE of $40 € / \mathrm{MWh}$ with the same FLh, may have a relatively small impact on $\mathrm{CO}_{2}$ capture cost, but would increase the SNG generation cost to 78 and $82 € / M W h$, respectively. Meanwhile DAC units could be located at the best electricity generation sites in the world. With the electricity generation equal to the first case and a $\mathrm{CO}_{2}$ cost of $100 € / \mathrm{t}_{\mathrm{CO} 2}$, SNG could be produced for a cost of $67 € / \mathrm{MWh}$, which is relatively cheaper. In addition, it needs to be further investigated whether it is appropriate to allocate the PtX plants close to the cement mills, since logistical infrastructure is needed to transport the synthetic fuels to the consumption sites. Some of the cement CCU potential may be lost due to such locational mismatches.

\section{Conclusions}

Carbon capture and utilisation represents an important potential approach via synthetic fuel generation from cement manufacturing process. Depending on scenarios, the fossil fuel consumption can be fully eliminated by the usage of waste and hydrogen, or a fully electric cement process. Emissions of the limestone cannot be fully compensated. Reaching a maximum potential peak in 2040, the production potential of synthetic hydrocarbon fuels from carbon captured in cement plants and electricity generated by renewables is between 3639 $\mathrm{TWh}_{\text {th }}$ and $7355 \mathrm{TWh}_{\text {th }}$ of liquid hydrocarbons, or $6298 \mathrm{TWh}_{\text {th }}$ and $12,723 \mathrm{TWh}_{\text {th }}$ of SNG with the peak in 2040, globally. A considerable additional energy demand is appended in order to produce the mentioned amounts of synthetic fuels, $6030 \mathrm{TWh}_{\mathrm{el}}$ to $12,189 \mathrm{TWh}_{\mathrm{el}}$ for liquids and $8238 \mathrm{TWh}_{\mathrm{el}}$ to $16,652 \mathrm{TWh}_{\mathrm{el}}$ for SNG, respectively in 2050. However, in a future energy system dominated by variable RE sources [10, 15], the costs of electricity would be 
significantly reduced. Production of synthetic fuels from captured $\mathrm{CO}_{2}$ can be done in accordance to the variable renewable resource availability, and further complement the energy system by functioning as a "virtual" chemical energy storage, in particular due to the synthetic fuel trading potential, as already discussed for the case of the Maghreb region [11] and in East Asia [67].

According to BP Energy Outlook 2017 [68], the global oil and gas demand in 2015 were about $52,500 \mathrm{TWh}_{\text {th }}$ and 38,600 $\mathrm{TWh}_{\text {th }}$, respectively. These would increase to 60,300 $\mathrm{TWh}_{\text {th }}$ and $53,200 \mathrm{TWh}_{\mathrm{th}}$ in 2035, respectively, according to the same source. In BP's best case scenario, 2035 could be the peak year of oil demand, with an almost even demand from 2030 to 2040. The highest synfuel generation potential from cement mill's $\mathrm{CO}_{2}$ emissions in 2040 is about $15 \%$ of oil demand or $28 \%$ of gas demand in 2035 . Nevertheless, it is expected that in a world with high shares of synthetic fuels, the light to medium transportation sector would be electrified and the oil demand for power generation is already substituted by renewable electricity. The electrification of marine, aviation and some parts of the industry would be still complicated or impossible, therefore a substantial hydrocarbon demand will remain even in a net zero GHG emissions scenario matching the Paris Agreement. However, only the nonenergetic demand for oil and gas in 2035 is expected to be around 10,600 TWh and $3600 \mathrm{TWh}$, respectively. This non-energetic oil demand solely exceeds the synfuel generation potential from cement $\mathrm{CO}_{2}$ emissions. Moreover, since the use of $\mathrm{CCU}$ for $\mathrm{PtX}$ does not entirely eliminate the $\mathrm{CO}_{2}$ emissions from the cement production, alternative uses for the $\mathrm{CO}_{2}$, or even alternatives to traditional cement and concrete, should be considered. In the discussion section, an array of options for $\mathrm{CO}_{2}$ utilisation is presented, as well as some of the alternatives to limestone for cement production. Moreover, the constant ongoing research on construction materials may provide more sustainable alternatives in the future.

The majority of PtX production potential (67\%) at the 2040 projected peak is concentrated in the SAARC region, Sub-Saharan Africa (ramping up) and Northeast Asia (despite the continuous decrease). Northeast Asia, dominated by China, experiences a reduction in synthetic fuel production potential from almost $39 \%$ of the global potential in 2015, down to less than $17 \%$ in 2050. North and South America show a rather stable potential throughout the projected years, while Eurasia, Europe and Northeast Asia experience a significant reduction in their synthetic fuel production potentials by 2050. The largest overall growth in synthetic fuel production potential by 2050 compared to 2015 can be expected for Sub-Saharan Africa, in the order of $800 \%$.

\section{Acknowledgements}

The authors gratefully acknowledge the public financing of Tekes (Finnish Funding Agency for Innovation) for the 'Neo-Carbon Energy' project under the number 40101/14. The authors would like to thank Manish Ram for proofreading.

\section{References}

[1] [IEA] - International Energy Agency, 2018. Technology Roadmap - Low-Carbon Transition in the Cement Industry, IEA, Paris. http://www.iea.org/publications/freepublications/publication/TechnologyRoadmapLo wCarbonTransitionintheCementIndustry.pdf.

[2] [IEA] - International Energy Agency, 2017. Key World Energy Statistics, IEA, Paris. https://www.iea.org/publications/freepublications/publication/KeyWorld2017.pdf . 
[3] G. Richards and I.E. Agranovski, 2017. Dioxin-like pcb emissions from cement kilns during the use of alternative fuels, Journal of Hazardous Materials 323, 698-709.

[4] D.L. Summerbell, C.Y. Barlow, J.M. Cullen, 2016. Potential reduction of carbon emissions by performance improvement: A cement industry case study, Journal of Cleaner Production 135, 1327-1339.

[5] R. Kajaste and M. Hurme, 2016. Cement industry greenhouse gas emissions management options and abatement cost, Journal of Cleaner Production 112, 40414052.

[6] S.A. Miller, V.M. John, S.A. Pacca, A. Horvath, 2017. Carbon dioxide reduction potential in the global cement industry by 2050, Cement and Concrete Research, in press, [https://doi.org/10.1016/j.cemconres.2017.08.026].

[7] R. Maddalena, J.J. Roberts, A. Hamilton, 2018. Can Portland cement be replaced by low carbon alternative materials? A study on the thermal properties and carbon emissions of innovative cements, Journal of Cleaner Production 186, 933-942.

[8] T. Gao, L. Shen, M. Shen, L. Liu, F. Chen, 2016. Analysis of material flow and consumption in cement production, Journal o Cleaner Production 112, 553-565.

[9] D. Song, J. Yang, B. Chen, T. Hayat, A. Alsaedi, 2016. Life-cycle environmental analysis of a typical cement production chain, Applied Energy 164, 916-923.

[10] Ch. Breyer, D. Bogdanov, A. Aghahosseini, A. Gulagi, M. Child, A.S. Oyewo, J. Farfan, K. Sadovskaia, P. Vainikka, 2017. Solar Photovoltaics Demand for the Global Energy Transition in the Power Sector, Progress in Photovoltaics: Research and Applications 26 (8), 505-523.

[11] M. Fasihi, D. Bogdanov, Ch. Breyer, 2017. Long-Term Hydrocarbon Trade Options for the Maghreb Region and Europe-Renewable Energy Based Synthetic Fuels for a Net Zero Emissions World, Sustainability 9(2), 306.

[12] N. Makul, P. Rattanadecho, D.K. Agrawal, 2014. Applications of microwave energy in cement and concrete - A review, Renewable and Sustainable Energy Reviews 37, 715733.

[13] S. Licht, H. Wu, Ch. Hettige, B. Wang, J. Asercion, J. Lau, J. Stuart, 2012. STEP cement: Solar Thermal Electrochemical Production of $\mathrm{CaO}$ without $\mathrm{CO}_{2}$ emission, Chemical Communications 48, 6019-6021.

[14] [UNFCCC] - United Nations Framework Convention on Climate Change, 2015. Adoption of the Paris Agreement - proposal by the president, UNFCCC, Paris, December 12, http://unfccc.int/resource/docs/2015/cop21/eng/109.pdf.

[15] M. Ram, D. Bogdanov, A. Aghahosseini, A.S. Oyewo, M. Child, H.J. Fell, Ch. Breyer. Global Energy System based on 100\% Renewable Energy - Power Sector. Study by Lappeenranta University of Technology and Energy Watch Group. Lappeenranta. Berlin. November 2017. Available online: http://bit.ly/2hU4Bn9.

[16] Zero Carbon Industry Plan: Rethinking Cement, 2017. Beyond Zero Emissions Inc. Fitzroy, Victoria, Australia. http://media.bze.org.au/ZCIndustry/bze-report-rethinkingcement-web.pdf.

[17] T. Marzi, G. Deerberg, C. Doetsch, A. Grevé, M. Hiebel, S. Kaluza, V. Knappertsbusch, D. Maga, T. Müller, H. Pflaum, A. Pohlig, M. Renner, U. Seifert, S. Stießel, C. Unger, T. Wack, E. Weidner, 2017. Kohlendioxid, Biomasse und regenerativer Strom Ressourcen einer neuen Kohlenstoffwirtschaft? Fraunhofer-Institut für Umwelt-, Sicherheits- und Energietechnik (UMSICHT), Oberhausen. www.umsicht.fraunhofer.de/content/dam/umsicht/de/dokumente/umsichtdiskurs/umsicht-diskurs-01-neue-kohlenstoffwirtschaft.pdf.

[18] H. El-Hassan, Y. Shao, 2015. Early carbonation curing of concrete masonry units with Portland limestone cement, Cement and Concrete Composites 62, 168-177. 
[19] Z. Ghouleh, R.I.L Guthrie, Y. Shao, 2017. Production of carbonate aggregates using steel slag and carbon dioxide for carbon-negative concrete, Journal of $\mathrm{CO} 2$ Utilization $18,125-138$.

[20] D. Zhang, Y. Shao, 2016. Early age carbonation curing for precast reinforced concretes, Construction and Building Materials 113, 134-143.

[21] H. El-Hassan, y. Shao, Z. Ghouleh, 2013. Effect of Initial Curing on Carbonation of Lightweight Concrete Masonry Units, ACI Materials Journal 110, 441-450.

[22] D. Leeson, N. Mac Dowell, N. Shah, C. Petit, P.S. Fennell, 2017. A Techno-economic analysis and systematic review of carbon capture and storage (CCS) applied to the iron and steel, cement, oil refining and pulp and paper industries, as well as other high purity sources, International Journal of Greenhouse Control 61, 71-84.

[23] J. Gibbins and H. Chalmers, 2008. Carbon capture and storage, Energy Policy 36, 43174322.

[24] Global Cement Directory, 2016. Pro Global Media Ltd, Surrey, United Kingdom. www.globalcement.com/directory.

[25] World Business Council for Sustainable Development, 2014. Cement Sustainability Initiative: Getting the Numbers Right (GNR) an independent database for the cement industry, Geneva, Switzerland. www.wbcsdcement.org/index.php/key-issues/climateprotection/gnr-database [Accessed June 2017].

[26] X. Liu, Z. Yuan, Y. Xu, S. Jiang, 2017. Greening cement in China: A cost-effective roadmap, Applied Energy 189, 233-244.

[27] M. Jibran, S. Zuberi, M.K. Patel, 2017. Bottom-up analysis of energy efficiency improvement and $\mathrm{CO}_{2}$ emission reduction potentials in the Swiss cement industry, Journal of Cleaner Production 142, 4294-4309.

[28] T. Gao, L. Shen, M. Shen, L. Liu, F. Chen, L. Gao, 2017. Evolution and projection of $\mathrm{CO}_{2}$ emissions for China's cement industry from 1980 to 2020, Renewable and Sustainable Energy Reviews 74, 522-537.

[29] B.J. van Ruijven, D.P. van Vuuren, W. Boskaljon, M.L. Neelis, D. Saygin, M.K. Patel, 2016. Long-term model-based projections of energy use and $\mathrm{CO}_{2}$ emissions from global steel and cement industries, Resources, Conservation and Recycling 112, 15-36.

[30] M. Fasihi and Ch. Breyer. Synthetic Methanol and Dimethyl Ether Production based on Hybrid PV-Wind Power Plants, $11^{\text {th }}$ International Renewable Energy Storage Conference, March 14-16, 2017, Düsseldorf, Germany. Available online: http://bit.ly/2qvsLYf.

[31] T. Schwartzböco, H. Rechberger, O. Cencic, J. Fellner, 2016. Determining national greenhouse gas emissions from waste-to-energy using the Balance Method, Waste Management 49, 263-271.

[32] M. Ozcan, 2016. Estimation of Turkey's GHG emissions from electricity generation by fuel types, Renewable and Sustainable Energy Reviews 53, 832-840.

[33] S. Weil, S. Hamel, W. Krumm, 2006. Hydrogen energy from coupled waste gasification and cement production - a thermochemical concept study, International Journal of Hydrogen Energy 31, 1674-1689.

[34] E. Gartner, 2004. Industrially interesting approaches to "low- $\mathrm{CO}_{2}$ " cements, Cement and Concrete Research 34, 1489-1498.

[35] J. Patricio, A. Angelis-Dimakis, A. Castillo-Castillo, Y. Kalmykova, L. Rosado, 2017. Region prioritization for the development of carbon capture and utilization technologies, Journal of $\mathrm{CO}_{2}$ Utilization 17, 50-59.

[36] A.M. Cormos, C. Dinca, L. Petrescu, D.A. Chisalita, S. Szima, C.C. Cormos, 2018. Carbon capture and utilisation technologies applied to energy conversion systems and other energy-intensive industrial applications, Fuel 211, 883-890. 
[37] A. Bosoaga, O. Masek, J.E. Oakey, 2009. $\mathrm{CO}_{2}$ Capture Technologies for Cement Industry, Energy Procedia 1, 133-140.

[38] Pro Global Media Ltd, 2014. China to stop production OPC 32.5 grade cement soon, Global Cement, Surrey, United Kingdom, April 30. www.globalcement.com/news/item/2460-china-to-stop-production-opc-325-gradecement-soon [Accessed September 2017].

[39] E.A. Asamany, M.D. Gibson, M.J. Pegg, 2017. Evaluating the potential of waste plastics as fuel in cement kilns using bench-scale emissions analysis, Fuel 193, 178186.

[40] A.A. Usón, A.M. López-Sabirón, G. Ferreira, E.L. Sastresa, 2013. Uses of alternative fuels and raw materials in the cement industry as sustainable waste management options, Renewable and Sustainable Energy Reviews 23, 242-260.

[41] W. Zhou, D. Jiang, D. Chen, C. Griffy-Brown, Y. Jin, B. Zhu, 2016. Capturing $\mathrm{CO}_{2}$ from cement plants: A priority for reducing $\mathrm{CO}_{2}$ emissions in China, Energy 106, 464 474.

[42] S. Licht, 2017. Co-production of cement and carbon nanotubes with a carbon negative footprint, Journal of $\mathrm{CO}_{2}$ Utilization 18, 378-389.

[43] Z. Cao, L. Shen, L. Liu, Sh. Zhong, 2016. Analysis on major drivers of cement consumption during the urbanization process in China, Journal of Cleaner Production 133, 304-313.

[44] A. Toktarova, L. Gruber, M. Hlusiak, D. Bogdanov, Ch. Breyer, 2018. Long-term load forecasting in high resolution for all countries globally, submitted.

[45] Jordbruksverket, 2007. Ekonomi-ekologisk Odling I växthus, Jönköping: Jordbruksverket Available at: [in http://www2.jordbruksverket.se/webdav/files/SJV/trycksaker/Pdf_jo/jo07_19.pdf [Accessed October 2017].

[46] H. El-Hassan and Y. Shao, 2014. Carbon storage through concrete block carbonation curing, Journal of Clean Energy Technologies 2, 287-291.

[47] V. Barbarossa, G. Vanga, R. Viscardi, D.M. Gattia, 2014. $\mathrm{CO}_{2}$ as carbon source for fuel synthesis, Energy Procedia 45, 1325-1329.

[48] J. Van-Heek, K. Arning, M. Ziefle, 2017. Differences between laypersons and experts in perceptions and acceptance of $\mathrm{CO}_{2}$-utilization for plastics production, Energy Procedia 114, 7212-7223.

[49] E. Alper and O.Y. Orhan, 2017. $\mathrm{CO}_{2}$ utilization: Developments in conversion processes, Petroleum 3, 109-126.

[50] N. Rodriguez, R. Murillo, J.C. Abanades, 2012. $\mathrm{CO}_{2}$ capture from cement plants using oxyfired precalcination and/or calcium looping. Environmental Science \& Technology 46, 2460-2466.

[51] K. Vatopoulos, E. Tzimas, 2012. Assessment of $\mathrm{CO}_{2}$ capture technologies in cement manufacturing process, Journal of Cleaner Production 32, 251-261.

[52] T.P. Hills, N. Florin, P.S. Fennel, 2016. Decarbonising the cement sector: A bottom-up model for optimising carbon capture application in the UK, Journal of Cleaner Production 139, 1351-1361.

[53] T.P. Hills, M. Sceats, Daniel Rennie, P.S. Fennel, 2017. LEILAC: Low Cost $\mathrm{CO}_{2}$ Capture for the Cement and Lime Industries, Energy Procedia 114, 6166-6170.

[54] P. Bains, P. Psarras, J. Wilcox, 2017. $\mathrm{CO}_{2}$ capture from the industry sector, Progress in Energy and Combustion Science 63, 146-172.

[55] A. Goeppert, M. Czaun, G.K.S. Prakash, G.A. Olah, 2012. Air as the renewable carbon source of the future: an overview of $\mathrm{CO}_{2}$ capture from the atmosphere, Energy and Environmental Science 5, 7833-7853. 
[56] F. Xi, S.J. Davis, P. Ciais, D. Crawford-Brown, D. Guan, C. Pade, et al, 2016. Substantial global carbon uptake by cement carbonation, Nature Geoscience 9, 880883.

[57] M. Fasihi, O. Efimova, Ch. Breyer, 2018. Techno-economic assessment of $\mathrm{CO}_{2}$ direct air capture plants, submitted.

[58] R. Socolow, M. Desmond, R. Aines, J. Blackstock, O. Bolland, T. Kaarsberg, N. Lewis et al., 2011. Direct Air Capture of $\mathrm{CO}_{2}$ with Chemicals - A Technology Assessment for the APS Panel on Public Affairs, The American Physical Society, June 2011, Maryland, United States.

[59] D.W. Keith, M. Ha-Duong, J.K. Stolaroff, 2006. Climate Strategy with $\mathrm{CO}_{2}$ Capture from the Air, Climatic Change 74, 17-45.

[60] A.J. Simon, N.B. Kaahaaina, S.J. Friedmann, R.D. Aines, 2011. Systems Analysis and Cost Estimates for Large Scale Capture of Carbon Dioxide from Air, Energy Procedia 4, 2893-2900.

[61] G. Holmes, D.W. Keith, 2012. An air-liquid contactor for large-scale capture of $\mathrm{CO}_{2}$ from air, Philosophical Transactions of the Royal Society A 370, 4380-4403.

[62] M. Mazzotti, R. Baciocchi, M.J. Desmond, R.H. Socolow, 2013. Direct air capture of $\mathrm{CO}_{2}$ with chemicals: optimization of a two-loop hydroxide carbonate system using a countercurrent air-liquid contactor, Climatic Change 118, 119-135.

[63] Climeworks AG, 2017. Online webpage: http://www.climeworks.com/co2-removal, Zürich. [Accessed on January 2018].

[64] G.F. Nemet, A.R. Brandt, 2012. Willingness to pay for a climate backstop: liquid fuel producers and direct $\mathrm{CO}_{2}$ air capture, The Energy Journal, 33 (1), 53-81.

[65] K.Z. House, A.C. Baclig, M. Ranjan, E.A. van Nierop, J. Wilcox, H. Herzog, 2011. Economic and energetic analysis of capturing $\mathrm{CO}_{2}$ from ambient air, Proceedings of the National Academy of Sciences (PNAS) 108, 20428-20433.

[66] Ch. Breyer, M. Fasihi, A. Aghahosseini, 2018. $\mathrm{CO}_{2}$ Direct Air Capture for effective Climate Change Mitigation: A new Type of Energy System Sector Coupling, The International Conference on Negative $\mathrm{CO}_{2}$ Emissions, May 22-24, Gothenburg, Sweden.

[67] A. Gulagi, D. Bogdanov, Ch. Breyer, 2017. Can Australia Power the Energy-Hungry Asia with Renewable Energy?, Sustainability 9, 233.

[68] BP, 2017. BP Energy Outlook - summary tables, BP, London, UK. Available online: https://www.bp.com/en/global/corporate/energy-economics/energy-outlook/energyoutlook-downloads.html [Accessed on January 2018]. 